\title{
SOEP
}

SOEPpapers

SOEPpapers
on Multidisciplinary Panel Data Research

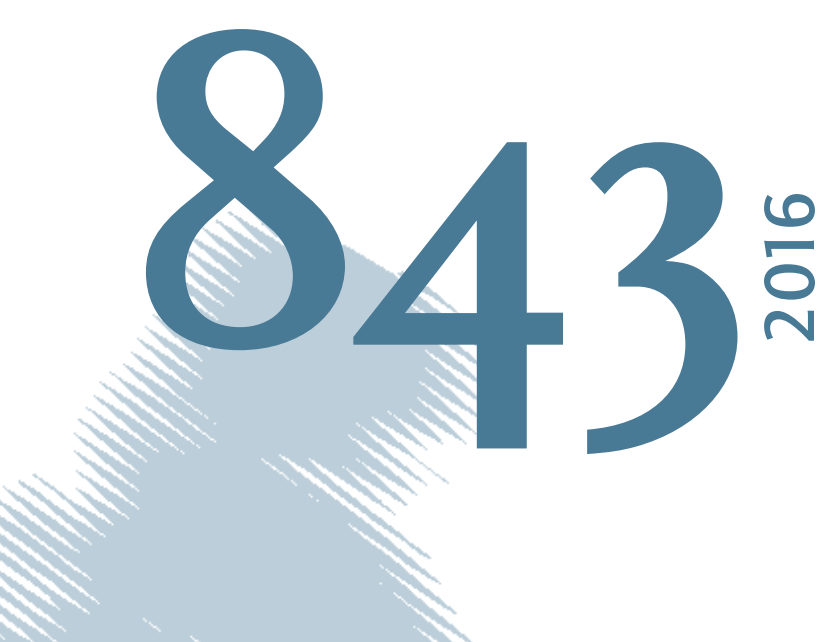

Ne

\section{Working-Time Mismatch and Mental Health}

Steffen Otterbach, Mark Wooden, Yin King Fok 
This series presents research findings based either directly on data from the German SocioEconomic Panel study (SOEP) or using SOEP data as part of an internationally comparable data set (e.g. CNEF, ECHP, LIS, LWS, CHER/PACO). SOEP is a truly multidisciplinary household panel study covering a wide range of social and behavioral sciences: economics, sociology, psychology, survey methodology, econometrics and applied statistics, educational science, political science, public health, behavioral genetics, demography, geography, and sport science.

The decision to publish a submission in SOEPpapers is made by a board of editors chosen by the DIW Berlin to represent the wide range of disciplines covered by SOEP. There is no external referee process and papers are either accepted or rejected without revision. Papers appear in this series as works in progress and may also appear elsewhere. They often represent preliminary studies and are circulated to encourage discussion. Citation of such a paper should account for its provisional character. A revised version may be requested from the author directly.

Any opinions expressed in this series are those of the author(s) and not those of DIW Berlin. Research disseminated by DIW Berlin may include views on public policy issues, but the institute itself takes no institutional policy positions.

The SOEPpapers are available at http://www.diw.de/soeppapers

\section{Editors:}

Jan Goebel (Spatial Economics)

Martin Kroh (Political Science, Survey Methodology)

Carsten Schröder (Public Economics)

Jürgen Schupp (Sociology)

Conchita D'Ambrosio (Public Economics, DIW Research Fellow)

Denis Gerstorf (Psychology, DIW Research Director)

Elke Holst (Gender Studies, DIW Research Director)

Frauke Kreuter (Survey Methodology, DIW Research Fellow)

Frieder R. Lang (Psychology, DIW Research Fellow)

Jörg-Peter Schräpler (Survey Methodology, DIW Research Fellow)

Thomas Siedler (Empirical Economics)

C. Katharina Spieß ( Education and Family Economics)

Gert G. Wagner (Social Sciences)

ISSN: 1864-6689 (online)

German Socio-Economic Panel (SOEP)

DIW Berlin

Mohrenstrasse 58

10117 Berlin, Germany

Contact: Uta Rahmann | soeppapers@diw.de

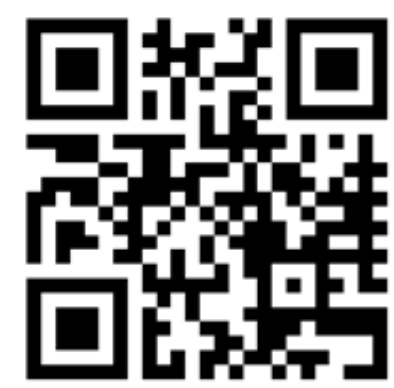




\title{
Working-Time Mismatch and Mental Health
}

\author{
Steffen Otterbach \\ Institute for Health Care \& Public Management \\ Universität Hohenheim \\ and \\ Institute for the Study of Labor (IZA) \\ Mark Wooden \\ Melbourne Institute of Applied Economic and Social Research, \\ University of Melbourne \\ and \\ Institute for the Study of Labor (IZA) \\ Yin King Fok \\ Melbourne Institute of Applied Economic and Social Research, \\ University of Melbourne
}

\section{March 2016}

\begin{abstract}
Nationally representative panel survey data for Germany and Australia are used to investigate the impact of working-time mismatches (i.e., differences between actual and desired work hours) on mental health, as measured by the Mental Component Summary Score from the SF-12. Fixed effects and dynamic linear models are estimated, which, together with the longitudinal nature of the data, enable person-specific traits that are time invariant to be controlled for. The incorporation of dynamics also reduces concerns about the potential effects of reverse causation. The results suggest that overemployment (working more hours than desired) has adverse consequences for the mental health of workers in both countries. Underemployment (working fewer hours than desired), however, seems to only be of significance in Australia.
\end{abstract}

JEL: I12; J22.

Keywords: Australia; Germany; mental health; Mental Component Summary Score (SF-12); longitudinal data; work hours; working-time mismatch.

\section{Acknowledgments}

This paper uses confidentialized unit record file data from both the Household, Income and Labour Dynamics in Australia (HILDA) Survey and the German Socio-Economic Panel (SOEP). The HILDA Survey Project was initiated and is funded by the Australian Government Department of Social Services (DSS) and is managed by the Melbourne Institute of Applied Economic and Social Research. The SOEP data were made available to us by the German Socio-Economic Panel Study team at the German Institute for Economic Research (DIW), Berlin.

The authors also thank Andy Charlwood for helpful comments and advice. 
Regulation of working time has long been a central focus of labor law, and in most industrial nations saw a convergence on the 5-day, 40-hour work week as the accepted standard or norm. In the latter decades of the $20^{\text {th }}$ century, however, the dominance of this full-time, 9-to5 model was challenged by the rapid growth in part-time work. Today part-time workers represent around $17 \%$ of all employed persons, when averaged across OECD nations. Concerns have also been expressed about the large proportions of workers (and especially men) who report regularly working far more than 40 hours a week. Long hours working is especially pronounced in East Asian countries (such as Japan and Korea), but is also a feature of many Western economies, including Australia, the UK and the USA.

While it is still widely believed that the 'best' jobs are those with weekly hours that most closely conform to industrial norms, there is also evidence that suggests that more important for worker well-being than the number of hours worked is whether, and the extent to which, those hours are aligned with worker preferences. Part-time work, for example, is often associated with low-quality employment, as reflected in low wages, poor levels of job security and a lack of opportunities for career development, yet studies of job satisfaction have mostly been unable to detect sizeable negative associations with part-time work. This, we suggest, should not be unexpected given the large majority of part-time workers have preferences for part-time hours. Some researchers, therefore, have focused on the underemployed - those part-time workers who are working fewer hours than desired arguing that the insufficiency of work among some part-time workers is analogous to unemployment. Thus underemployment, like unemployment, is a source of stress that has the potential to compromise health and well-being.

Similarly, while there is a large body of evidence demonstrating positive associations between long hours of work and both the incidence of work-related injury and symptoms of health problems, relatively new research, based on household panel survey data, suggests that 
it is only when hours diverge from preferences that any strong associations between long hours and measures of job satisfaction and life satisfaction are obvious. Whether such findings also extend to health outcomes, and in particular psychological health, is less clear. Existing evidence is both limited and inconclusive, restricted to just two studies of the same UK data source that reached quite different conclusions.

In this study we seek to add to this small literature. Specifically, we seek to test the twin hypotheses that psychological health is affected by working-time arrangements, and that it is the degree of mismatch between usual and preferred working time hours, rather than the number of hours usually worked, which is most critical. The key feature of the analysis is the use of comparable representative longitudinal data for two very different populations Australia and Germany - where very different regulatory arrangements prevail. The use of longitudinal data enables estimation of models that hold constant time-invariant individualspecific traits, and thus better deals with unobserved heterogeneity. It also enables the estimation of models that incorporate simple dynamic processes and thus reducing concerns about the potential for reverse causation.

\section{Previous Research}

Organizational psychologists have long argued that work outcomes will be influenced by the compatibility between people and both the characteristics of their jobs and the organizations they work for, and that incongruence in the person-to-job fit can be a source of dissatisfaction and stress (e.g., Edwards 1991; Kristof 1996). It thus follows that the inability of some workers to find work that satisfies their working-time preferences should also be a source of dissatisfaction and stress. Despite this, and until relatively recently, most empirical research on working-time mismatch focused on only one side of the dimension underemployment. 
Reviews of this literature generally suggest a mixed picture. Anderson and Winefield (2011: 173), for example, claimed that on balance there has only been "moderate support for the notion that underemployment affects psychological well-being”. Similarly, Friedland and Price (2003: 34), when summarizing research from cross-sectional studies conducted in the 1980s and 1990s, concluded that findings provide "mixed support for the assumption that underemployment is harmful for the health and well-being of workers”. Both reviews highlighted the dominance of cross-sectional research designs and the difficulty in drawing causal inferences from such research, and pointed to the importance of research utilizing longitudinal data. Included here are studies employing samples of young people from the US National Longitudinal Study of Youth (e.g., Prause and Dooley 1997; Dooley, Prause and Ham-Rowbottom 2000), which attempted to deal with causation by examining the association between underemployment and outcomes at one point in time, while including a control for the outcome variable measured at an earlier time. These studies suggest negative effects of underemployment on measures of self-esteem and depression. Less clear is whether these effects are replicable within older populations.

Somewhat surprisingly, only recently have researchers begun examining whether overemployment, the flip-side of time-related underemployment, might also be associated with adverse outcomes. Indeed, the first study to examine the effects of both underemployment and overemployment on a range of well-being outcomes - Friedland and Price (2003) - was motivated primarily by an interest in underemployment. Further, that study, despite its seminal nature, was not very convincing. The sample, while representative of the US population aged 25 years or older, was relatively small $(\mathrm{N}=1429)$, and controls were restricted to a handful of personal characteristics. But perhaps most importantly, while this study, like the earlier studies of NLSY data by Prause and Dooley (1997) and Dooley et al. (2000), utilized longitudinal data and conditioned on prior health, the estimation methods 
employed were still cross-sectional. They did not utilize the panel nature of the data to control for unobserved heterogeneity. Perhaps as a result of these weaknesses, some of the findings reported were unexpected. Working fewer hours than desired in part-time jobs, for example, was found to be significantly, but positively, associated with job satisfaction, something that runs counter to both expectations and other research. Overemployment, which Friedland and Price (2003) defined as working both at least 45 hours per week and more hours than desired, on the other hand, exhibited significant associations in the expected direction with both job satisfaction (negative) and a measure of chronic disease (positive), but, in contrast to expectations, was found to be inversely associated with a measure of depression. We suspect such results may be a function of omitted variables and the potentially endogenous nature of the underemployment and overemployment variables.

More recent studies have dealt with the issue of omitted variables by making use of annual data from household panel surveys undertaken in Australia (the Household, Income and Labour Dynamics in Australia [HILDA] Survey), Germany (the Socio-economic Panel [SOEP]) and the UK (the British Household Panel Study [BHPS]), all of which collect data on working-time preferences, and then estimating panel data models that hold constant all between-person differences that are time invariant. In these datasets the question on workingtime preferences is always conditioned on income, though arguably not very well in the case of the BHPS (see Angrave and Charlwood 2015: 1495). Further, in these studies, the definition of underemployment and overemployment is not conditioned on actual hours of work (though many of these studies do interact underemployment and overemployment with weekly hours worked). The dependent variables used vary across studies, but cover the same range of outcomes originally considered by Friedland and Price (2003) - namely, measures of job satisfaction, life satisfaction, subjective health and psychological health. 
Taking each of these broad outcome types in turn, Green and Tsitsianis (2005) examined influences on job satisfaction using 11 annual waves of data for Britain from the BHPS, and 17 years of data for Germany from the SOEP. They found working-time mismatch was associated with significantly lower levels of job satisfaction, but with working too many hours (overemployment) having more of an adverse effect than working too few hours (underemployment) in both Britain and West Germany. In contrast, in East Germany overemployment was not associated with job satisfaction. Negative effects of working-time mismatch on job satisfaction were also reported by Cornelißen (2009), who used SOEP data, though he did not distinguish between underemployment and overemployment, and by Angrave and Charlwood (2015), who used BHPS data and, like Green and Tsitsianis (2005), concluded that overemployment was of greater consequence than underemployment. Similarly, Wooden, Warren and Drago (2009), in their analysis of data from Australia (HILDA Survey), also reported strong negative associations between working-time mismatch and job satisfaction. However, they found that once the size of the mismatch was accounted for, there was little difference between underemployment and overemployment - one hour of underemployment had about the same impact on job satisfaction as one hour of overemployment.

Effects of working-time mismatch on broader measures of subjective well-being, such as overall life satisfaction, would be expected to be smaller, and in general research is consistent with this. Both Wooden et al. (2009) and Angrave and Charlwood (2015), for example, examined associations with both job satisfaction and life satisfaction, and found noticeably smaller (but still statistically significant) associations with overall life satisfaction. Less clear is whether it is overemployment or underemployment that is more important. Wooden et al. (2009) reported that an hour of overemployment is more damaging for life satisfaction than an hour of underemployment, especially among men. Evidence from Germany, however, 
suggests the opposition conclusion. Indeed, Wunder and Heineck (2013) reported no significant association with overemployment in their sample of married Germans with children. Subsequent comparative research by Kugler, Wiencierz and Wunder (2014), employing semi-parametric estimation methods, appears to confirm these cross-country differences, with the life satisfaction scores of Australian workers being much less responsive to underemployment, whereas the well-being of German workers, and especially men, appears not to respond to overemployment at all.

Very different are the studies of Robone, Jones and Rice (2011) and Bell, Otterbach and Sousa-Poza (2012), which focused on subjective measures of health. Both examined an identically worded measure of self-reported health scored on a 5-point scale, with Robone et al. (2011) using data from the BHPS and Bell et al. (2012) data from both the BHPS and SOEP. While different types of models were estimated - Robone et al. (2011) estimated a dynamic model with correlated random effects while Bell et al. (2012) estimated conventional fixed effects and fixed effects ordered logit models - both found that a desire for fewer hours is associated with worse self-reported health (though the magnitude of these associations could be argued to be small). With respect to underemployment, both reported significant negative associations, but only for men in the BHPS data. In the SOEP data, on the other hand, negative associations were also reported for women.

Finally, both Robone et al. (2011) and Angrave and Charlwood (2015) used the BHPS data to identify associations between working-time mismatch and psychological health, where the latter was measured using the 12-item General Health Questionnaire (GHQ-12), a self-administered instrument that has been widely used to screen for common mental health disorders. Despite use of a common data source, the findings suggest quite different conclusions. Angrave and Charlwood (2015) found that working-time mismatch was generally negatively associated with GHQ-12 scores, but with effects more pronounced for 
overemployment. Indeed, among men there was little evidence that underemployment was negatively associated with the GHQ-12. Robone et al. (2011), on the other hand, reported no evidence of statistically significant associations between working-time mismatch and GHQ12 scores among British men. Further, for women they found that the adverse association with overemployment was strongest for those working part-time hours. These different findings almost certainly reflect differences in model specification; with Robone et al. (2011) lagging all measures of working conditions, including work hours preferences, by one period.

In summary, during the last decade, research based on household panel survey data has highlighted the possible negative effects of working-time mismatch on worker well-being. This body of evidence is relatively small, and focused mainly on evaluative measures of satisfaction with jobs and life more broadly. But if working-time mismatches are a source of psychological stress, associations with more direct measures of psychological health might be expected to be stronger than with global evaluative measures of life. The panel-data evidence on the effects of mismatch on psychological health that does exist, however is based on the same data source (from the UK) and gives rise to conflicting conclusions. This study seeks to add to this literature by employing data from two other data sources and countries and involving a comparable measure of psychological health - the Mental Component Summary score from the SF-12. Further, we test how sensitive results are to model specification, estimating both fixed effects models and dynamic panel data models with correlated random effects.

\section{Methods}

To model mental health we make use of two different, but related, estimation methods designed for panel data. First, and following the approach used by Wooden et al. (2009), Bell 
et al. (2012) and Angrave and Charlwood (2015), we estimate a model that includes an individual-specific effect. This takes the form:

$$
y_{i t}=\beta^{\prime} x_{i t}+\gamma^{\prime} Z_{i t}+\phi_{t}+\alpha_{i}+\varepsilon_{i t} ; \quad i=1, \ldots, \mathrm{N} ; t=1, \ldots, \mathrm{T}
$$

where $y_{i t}$ is a measure of mental health, $x_{i t}$ is a vector of time-varying variables capturing working time mismatch, $z_{i t}$ is a vector of other time-varying exogenous variables that are hypothesized to influence the outcome, $\alpha_{i}$ are individual-specific constants, $\phi_{t}$ captures any time-specific (survey wave) effects, and $\varepsilon$ it is a random error term.

As argued by Robone et al. (2011), an obvious criticism of this type of specification is that it may be affected by endogeneity bias; in particular, desired working hours (and hence working time mismatch) may be a function of mental health status. To address such concerns, we also estimate dynamic panel data models with correlated random effects, as set out in equations (2a / 2b).

$$
\begin{aligned}
& y_{i t}=\delta y_{i t-1}+\beta^{\prime} x_{i t}+\gamma^{\prime} z_{i t}+\phi_{t}+\alpha_{i}+\varepsilon_{i t ;} \quad i=1, \ldots, \mathrm{N} ; t=1, \ldots, \mathrm{T} \\
& \alpha_{i}=\alpha_{0}+\alpha_{1} y_{i 1}+\alpha_{2} \bar{z}_{i}+\mu_{i}
\end{aligned}
$$

This specification allows current mental health status to be a function of mental health status in the previous period. Estimation of 2a with a conventional fixed-effects (or randomeffects) model, however, will produce biased estimates because the values of the lagged dependent variable will not be independent of $\alpha_{i}$. Instead, and as in Robone et al. (2011), we adopt the approach recommended by Wooldridge (2005) and model the distribution of the unobserved individual-specific effects $\left(\alpha_{i}\right)$ as a function of both the initial value of the outcome variable, which is proxied by the first observed value of the mental health variable within the panel for each individual ( $\left.y_{i 1}\right)$, and the within-person means of all exogenous timevarying variables $\left(\bar{Z}_{i}\right)$. This model is then estimated with the random-effects estimator. 


\section{Data}

\section{Samples}

The data for this study are drawn from two well-known household panel surveys: the German Socio-Economic Panel (SOEP) and the Household, Income and Labour Dynamics in Australia (HILDA) Survey (Wagner, Frick and Schupp 2007; Watson and Wooden 2012). While there are numerous differences in the way the two surveys are designed and administered, they have many common features (see Watson and Wooden 2014). Notably both commenced with nationally representative samples of private households, and then sought to re-interview all adult members of those households (together with any other coresidents) every year thereafter. Importantly, the two studies have a very similar focus on work, income and well-being, and thus contain many common variables. Most critical for this analysis, both surveys collect data on usual and preferred working hours, and in recent waves, provide a common mental health measure.

While the SOEP commenced in 1984, in this analysis we only make use of observations from six survey waves: 2002, 2004, 2006, 2008, 2010 and 2012. This reflects the availability of data on the key mental health outcome that is central to this study (see below). After restricting the sample to what might be loosely described as the working age population persons aged between 17 and 64 years of age (where age is measured as survey year minus birth year) - and excluding any cases with missing observations on the mental health outcome variable, we are left with an initial sample comprising 96,847 observations covering 32,500 individuals.

The HILDA Survey, in contrast, only commenced in 2001, but provides information on mental health states in all waves. Applying the same sample restrictions as those applied to the SOEP data, but covering all survey waves between 2001 and 2013, gives us an initial sample comprising 125,174 observations covering 22,416 individuals. If we further restrict 
the sample to only include observations from the same six survey years available for the SOEP analysis, we are left with 56,268 observations from 18,661 individuals.

\section{Measurement of Mental Health}

The principal outcome variable for this analysis is the Mental Component Summary (MCS) score from the 12-item version of the Medical Outcomes Study Short Form Health Survey (SF-12). Score values range from 0 to 100 with the mean value and standard deviation in the base year (which in this analysis is 2004) set to 50 and 10 respectively. ${ }^{1}$

The SOEP administers version 2 of the SF-12 whereas the HILDA Survey administers version 1 . As a result, the underlying questionnaire items, while very similar, are not identical in the two surveys. There are also differences in the way the SF-12 data are collected in the two studies. The HILDA Survey administers the SF-12 as part of the longer SF-36 instrument. More importantly, it is administered not as part of the main interview, but as part of a separate self-completion instrument. All responses are thus obtained without the assistance of an interviewer. In contrast, the SOEP administers the SF-12 as part of its main interview, which, in turn, is delivered by a variety of different modes, but with more than half involving interviewer administration. ${ }^{2}$ This may lead to some overstatement of mental health in the SOEP data relative to the HILDA Survey given evidence that respondents tend to exaggerate their health when responding to an interviewer relative to what is recorded on a paper or online instrument completed by the respondent in their home (e.g., Lyons et al. 1999; Cernat, Couper and Ofstedal 2015).

\footnotetext{
${ }^{1}$ The algorithm used to construct the MCS using the GSOEP data is described in Andersen et al. (2007). We have applied the same algorithm to the HILDA Survey data.

${ }^{2}$ Fifty-two percent of respondents in our SOEP sample were interviewed by an interviewer (32\% by computerassisted methods and $20 \%$ by pen-and-paper methods), $28 \%$ of respondents completed the questionnaire themselves without the assistance of the interviewer, $3 \%$ completed the questionnaire themselves but with the assistance of an interviewer, and about $14 \%$ provided written questionnaires returned by mail. A further $3 \%$ were completed using a mixture of survey modes.
} 


\section{Measurement of Working Hours and Working-time Mismatch}

Working hours are based on self-reports of the number of usual or average hours worked in a week. In the HILDA Survey the question relates to a usual week, covers both paid and unpaid overtime, and relates to all jobs currently held (i.e., during the 7 days preceding interview). In the SOEP the relevant question (at least when correctly translated) refers to "average working hours including possible over-time”. This question does not specify whether unpaid hours are included, but a subsequent question about whether overtime hours are compensated for makes it clear that the intent is that all hours are to be included. Also unclear is whether the working hours relate to only one job or all jobs. Again, subsequent questions imply that the intent here is only to measure hours worked in the main job, and hence hours of work will be under-counted relative to the HILDA Survey.

Respondents to both surveys are also asked, if currently employed, about the number of hours they would prefer to work each week, after taking into account any effects on income. Another difference between the two surveys is that responses to this question in the HILDA Survey are conditioned on respondents first indicating that they would prefer to worker fewer or more hours than currently.

Similar to previous research (e.g., Wooden et al. 2009; Bell et al. 2012; Angrave and Charlwood 2015), our main specification (specification I) includes a series of dummy variables that interact usual weekly work hours categories with mismatch status (underemployed, matched, or overemployed). Following Bell and Freeman (2001) and Bell et al. (2012), we only classify someone as mismatched if the discrepancy between actual and desired hours is at least four hours per week. We also retain persons who are not employed at the time of interview by setting their working hours to zero and including two dummy 
variables identifying, respectively, persons who are unemployed (i.e., actively looking for a job) and persons who are not in the labour force. ${ }^{3}$

We also consider an alternative specification (specification II) where, following Wooden et al. (2009), we include separate measures of the extent (i.e., hours) of underemployment and of overemployment. ${ }^{4}$ In this specification we also include controls for usual hours worked (three categorical dummy variables).

\section{Covariates}

Given the fixed-effects estimation approach, our set of covariates consists of a parsimonious set of time-varying covariates. These measure: age (four categorical dummies); marital / relationship status; the number of dependent children (under 17 years of age, where age is again survey year minus birth year); the presence of a disability; the log of real annual equivalized net household income (where the equivalence scale applied is the square root of household size and nominal incomes are adjusted using the official consumer price index in each country ${ }^{5}$ ); and, if employed, occupation (27 two-digit occupation dummies using the 1988 International Standard Classification of Occupations). In addition, we also include a set of survey year dummies. Summary statistics describing all variables are provided in Appendix Table A1.

While we have attempted to ensure that variables are comparable across the two datasets, differences in questionnaire design and in institutional arrangements mean this is not always

\footnotetext{
${ }^{3}$ The definition of unemployment used in both samples follows ILO concepts, and thus requires both active job search and availability to start work. There are, however, subtle differences across the two surveys. In the SOEP sample, an unemployed person is anyone who is not employed (or involved in compulsory military service or community service) and who states that they both actively looked for work within the last four weeks and are available to start work within the next two weeks. In the HILDA Survey sample, unemployment requires: (i) active job search during the preceding four weeks, but where active job search is based on the method of job search reported; and (ii) being available to start work within the previous week, or waiting to start a new job within the next four weeks.

${ }^{4}$ In these analyses we do not set any minimum threshold in order to be classified as under or overemployed.

${ }^{5}$ The base period (CPI=100) selected for the SOEP was the 2012 calendar year while for the HILDA Survey it was the 2011/12 financial year.
} 
possible. The relationship status variable for the SOEP identifies persons who are in a registered marriage and live with their spouse. It thus excludes de facto unions. ${ }^{6}$ By contrast, the comparable variable for the HILDA Survey dataset includes both registered marriages and de facto unions, and reflects the fact that in Australia there are few (if any) differences between these two types of unions in terms of legal entitlements.

The disability variable in the SOEP data is based on whether respondents have been 'legally assessed as handicapped' or partially incapable of work, and on the extent of that reduced capability. According to German social law, a disability exists when limitations in physical functioning, mental capability or emotional health are present that have lasted, or with a high probability are expected to last, longer than 6 months, and therefore restrict individuals’ participation in social and professional life. The degree of limited functioning (ranging from 10 to 100 in steps of 10) is based on an official assessment by authorized experts and doctors. Individuals are considered as disabled if their degree of limited functioning is $20 \%$ or higher. In Australia, on the other hand, there is no official system for recognizing and quantifying the extent of disability. Instead, disability within the HILDA Survey data has been determined by respondents reporting the presence of a long-term health condition or disability that restricts every day activity, has lasted (or is expected to last) 6 months or more, and limits the type of amount of work that can be done to at least some extent. Relative to the SOEP measure, this will almost certainly mean more workers being classified as disabled.

Finally, while the household income variables used are conceptually the same, providing estimates of the combined income of all household members from all regular income sources (labor earnings, asset flows, private retirement income, private transfers, public transfers, and

\footnotetext{
${ }^{6}$ From 2011 onwards the SOEP question on marital status was changed to also include an option for registered partnerships. However, for reasons of longitudinal consistency we have opted not to change the coding of this variable.
} 
social security pensions) minus taxes paid over a 12 -month period ${ }^{7}$, there are likely to be differences across the two studies in coverage. Both variables are also underpinned by considerable imputation (for both item non-response due to missing components and unit non-response within households). Further, neither study directly collects data on taxation; rather these are estimated based on individual and household circumstances and the taxation rules in effect in each country at the time of each interview. ${ }^{8}$

\section{Results}

We begin our presentation of results by reporting, in Table 1 , descriptive data on both the incidence of working-time mismatches and the distribution of working hours for the employed subsets of our two population samples, disaggregated by sex. If we focus first on the numbers reported in the final column in this table, it can be seen that the distribution of working time is surprisingly similar in the two countries. Both populations are characterized by relatively high levels of part-time work (defined here as less than 35 hours per week), especially among women, and relatively high levels of long hours working (defined as 50 hours or more per week). The incidence of both part-time hours and long hours is greater in Australia, but the differences are not large.

More importantly, Table 1 also shows that work hours mismatches are very common in both countries, with only around $60 \%$ of the Australian workforce and less than half of the German workforce working their desired weekly hours of work. In the Australian sample about $28 \%$ of employed men and $25 \%$ of employed women report being overemployed - that is, usually working more hours than preferred. The comparable numbers for the German sample are considerably larger; $48 \%$ of employed men and 38\% of employed women. These

\footnotetext{
${ }^{7}$ The reference period is the financial year preceding interview, which in the SOEP is the calendar year and in the HILDA Survey is the year ended 30 June.

${ }^{8}$ Taxes in the SOEP are derived using updated and modified calculation routines developed originally by Schwarze (1995). The taxation estimation routines used in the HILDA Survey are described in detail in Wilkins (2014).
} 
high levels of overemployment reflect the sizable fractions of the workforce who regularly work long hours, with the incidence of overemployment rising with the number of hours worked. Underemployment, on the other hand, is less common, with about $13 \%$ of employed men and $15 \%$ of employed women in Australia, and $8 \%$ of employed men and $17 \%$ of employed women in Germany, reporting working fewer hours than desired.

[Table 1 about here]

We now turn to the results of our regression models. We begin by reporting results from fixed-effects estimation. As noted earlier, two specifications are estimated; specification I includes a series of dummy variables that interact usual weekly work hours categories with mismatch status (Table 2), while specification II replaces these interaction terms with two variables measuring the size of mismatch, while also controlling for the number of weekly hours usually worked (Table 3). Note that the sample includes all persons, and not just persons in employment at each survey wave, and hence additional controls are included identifying both the unemployed (i.e., job seekers) and those not currently in the labour force (i.e., neither employed nor seeking work). As we would expect, the coefficients on these variables are negatively signed, though in the German sample it is only the unemployment variable that is statistically significant. The results on other controls also mostly accord with expectations, with mental health scores for both men and women, and in both samples, found to be positively associated with marriage and household income, and negatively associated with the presence of a disability. No significant associations, however, were found with the number of children, and with the exception of Australian men, there was no evidence of any significant association with age. 
Focusing now on the variables of most interest to this study - the interactions between working hours and working time mismatch - the estimated coefficients exhibit a similar pattern across both samples, and for both men and women. Compared with the reference category - employed persons who usually work 35 to 40 hours each week and report that these are their preferred hours - it is the overemployed who stand out as most different. Among men, those working full-time hours who report working more hours than desired have significantly lower mental health scores than workers in the reference category, and these effects appear to be somewhat larger in Germany than in Australia (at least among men working 41 to 49 hours a week). The magnitudes of these negative effects are even larger among women, and are not just restricted to those working full-time hours. The sizes of these effects are also larger in Germany than in Australia, at least among women working more than 40 hours a week. In contrast, there is no evidence of any consistent and significant association between mental health scores and underemployment.

[Table 2 about here]

As discussed by Wooden et al. (2009), one weakness of specification I is that it assumes work hours mismatches have the same impact on mental health regardless of the magnitude of the discrepancy between actual and desired work hours. Therefore, in Table 3 we report the results of our alternative specification in which we replace the interactions between actual hours worked and mismatch status with two continuous variables measuring the extent of underemployment and overemployment (specification II). Consistent with the results reported in Table 2, we find that among German workers it is only hours of overemployment that are negatively associated with mental health scores, and the magnitude of this effect is larger among women than men. In the Australian sample, however, hours of both underemployment 
and overemployment matter, and the magnitudes of these two effects are very similar - a result which is also reported by reported by Wooden et al. (2009) with respect to a subjective measure of life satisfaction. Further, the magnitudes of these effects vary little between men and women; among Australian women, overemployment seems to have a more detrimental effect on mental health than underemployment, but the size of this difference is not statistically significant.

The results presented in Table 3 also highlight far more clearly cross-country differences, with the negative associations between overemployment and mental health being about twice as large in Germany than in Australia. Conversely, the (smaller) negative association between underemployment and mental health is about twice as large in Australia than in Germany.

[Table 3 about here]

Given the concerns about the potential for reverse causality, we next report results of correlated random effects models that include previous mental health lagged one period as well as the first observation of mental health within our panels. The results from the estimation of specifications I and II are reported in Tables 4 and 5, respectively. As expected, in all cases both the initial and lagged mental health scores are positively associated with current mental health. Note further that the signs and significance of the control variables are mostly unchanged from those reported in Tables 2 and 3. There are, however, two notable exceptions here. First, and much to our surprise, within the German samples, unemployment is no longer significant, suggesting that once previous mental health states is controlled for, unemployment is no longer a significant influence on mental health. But why this result only occurs in our German sample is difficult to explain. Second, among Australian men the 
number of dependent children now emerges as a significant negative influence on mental health states

Much more important for this analysis are the results on the variables measuring workingtime mismatch, and again we draw the conclusion that for the most part it is only the size of the coefficients that are affected by the choice of estimation method and not their signs or significance. Overemployment thus again emerges as a significant negative influence on mental health, and much more so than underemployment. That said, the results in Table 4 do suggest a slightly larger negative impact of underemployment on mental health than was suggested by the results reported in Table 2. In particular, among German men, there is some evidence that working fewer hours than desired is negatively associated with mental health, but surprisingly such findings are restricted to those working full-time hours. In contrast, and in line with expectations, among Australian women we now find evidence of a significant, but modest, negative association between underemployed part-time hours and mental health.

[Tables 4 and 5 about here]

Finally, estimation of specification II using the dynamic correlated random effects model (see Table 5) continues to suggest that in Germany it is only overemployment that has harmful consequences for mental health; indeed among German women, there is a weak positive association between the number of underemployed hours and mental health. In contrast, and similar to what was reported in Table 3, in Australia one hour of overemployment has much the same effects as one hour of underemployment. And again, we emphasise that the negative effects of overemployment are much larger in Germany (about double the magnitude of the effect in Australia). 


\section{Robustness Checks}

To check the robustness of our results, we also repeated the analyses on a number of modified samples and using a range of different specifications. The results of these additional analyses are reported in an Appendix.

First, we tested whether use of biennial rather than annual data had any impact on our findings. We thus replicated the Australian results after including all 13 available surveys waves of the HILDA Survey data. These results are reported in Appendix Tables A2 (specification I) and A3 (specification II). With one small exception, the pattern of results is largely unchanged from those reported using biennial data. The exception is that in specification I the coefficients on the underemployment variables tend to be both larger and more likely to be significant. This is especially so among male workers and those working part-time hours.

Second, we examined whether the results were sensitive to sample selection and more specifically, the inclusion of younger individuals who, on average, will be relatively recent labour market entrants, some of whom will still be engaged in study and training. We thus replicated the fixed-effects estimation of specification I after excluding all observations where the respondent was aged less than 25 years. Comparison of these results (reported in Appendix Table A4) with those reported in Table 2 reveal no differences of any note. The estimated magnitudes of coefficients change, but the pattern of signs and significance on these coefficients is unaffected.

Third, we also checked whether results would be any different if the sample was restricted to employed persons. Again, comparison of results from fixed-effects models (compare Appendix Table 5 with Table 2) reveals few differences of importance, though there is evidence in the alternative specification that underemployment among persons working a 35 
to 40 hour week is associated with lower mental health scores among men in both the Australian and German samples.

Fourth, it might be argued that the assumption of a linear relationship between the number of hours of underemployment or overemployment and mental health in specification II is inappropriate. We, therefore estimated an alternative specification where the continuous measures of working time mismatch were replaced with a series of dummy variables identifying whether the extent of underemployment or overemployment was less than 5 hours, 5 to 9 hours, 10 to14 hours, 15 to 19 hours, or 20 hours or more. The results from the fixed-effects estimation of this alternative specification are reported in Appendix Table A6. The results for the German sample are entirely consistent with those reported in Table 3. Thus underemployed workers, regardless of the extent of that underemployment, do not have mental health scores that are any different from the reference category (workers in jobs where usual weekly hours precisely match preferences). Overemployed workers, on the other hand, have significantly lower mental health scores than workers in the reference category and the extent of this 'penalty' increases more or less in a linear fashion with the number of overemployed hours. In contrast, the estimates for the Australian sample suggest a very different pattern. Among men there is a sizeable underemployment penalty, but only when the extent of mismatch is large (20 hours or more per week), while the penalty for overemployment kicks in at quite low levels of mismatch (at least 5 hours per week) and does not grow with the extent of mismatch. A similar pattern is found for Australian women, though in their case the threshold for the underemployment penalty is slightly lower (a gap of around 15 hours) and the penalty for overemployment exists even when the extent of mismatch is very small.

Finally, a potentially major issue for all survey-based analyses, but especially those using longitudinal data, is the possibility of bias arising from non-random response and attrition. As 
a check for such biases we re-estimated all models after applying the recommended longitudinal weights provided with the data. We, however, only report here the weighted results for the fixed-effects estimation of specification I. These are reported in Appendix Table A7, and should be compared with the unweighted results reported in Table 2. Note that sample sizes decline markedly in the presence of weights. This is a function of the way the longitudinal weights are constructed, with a weight of zero assigned to most individuals not observed in all of the waves covered by our analysis. As a result, the standard errors of our estimates mostly increase. Despite this, however, the weighted results do not suggest any marked change in our conclusions is warranted. This, in turn, suggests that any effects of non-random response are modest.

\section{Discussion and Conclusions}

We have found clear evidence that overemployment is associated with adverse mental health outcomes for workers in Germany and Australia, and it is mismatch rather than the numbers of hours worked each week that is critical. Indeed, these negative associations between overemployment and mental health were not just limited to persons working very long weeks, but were also found among persons working what are traditionally regarded as standard work weeks and even part-time workers, especially women. Further, these findings with respect to overemployment are strikingly similar to what Angrave and Charlwood (2015) found in UK data using a similar approach and specification to that used here.

Less clear is how large these associations are. For the overemployed working long hours (50 or more per week) the estimated coefficients fall in the range of -.9 to -1.5 for men, and 1.3 to -1.7 for women. When judged against a standard deviation of 10 in the outcome variable, these magnitudes might be considered relatively small. That said, given fixedeffects estimation, a better comparison is with the standard deviation in the within-person 
mean, which is considerably smaller - around 5.6 and 5.9 in Australia and Germany, respectively. Further, the coefficients are relatively large when compared with the estimated coefficients on covariates; the onset of a long-term health condition or disability, for example, is only associated with coefficients in the range of -1.5 to -2.5 .

The results also suggest that underemployment is less important than overemployment, especially in Germany. Indeed, among German workers we were unable to find any strong evidence that working fewer hours than desired exhibited any association with mental health scores. In contrast, among Australian workers significant negative effects were found, among both men and women, once underemployment was specified as a continuous variable. Indeed, in Australia an hour of underemployment was found to have about the same effect on mental health as an hour of overemployment.

That our findings for the Australian and German samples are different should not be surprising given the marked differences in the institutions that influence and shape labour market outcomes in these two countries. The much larger penalty associated with underemployment in Australia, for example, possibly reflects the pervasive use of casual employment in that country. Just over $18 \%$ of the employed HILDA Survey sample are casual employees, whose hours of work can be varied at any time and who typically do not have entitlements to any forms of paid leave. This is quite different to Germany where there are very few employees whose working hours can be so readily varied by their employers and who do not have leave entitlements. While temporary employment is relatively common in Germany, these workers mostly have fixed-term contracts with clear end dates and with access to the same sorts of entitlements (e.g., leave) as other workers (about 12\% of our SOEP sample are employees on fixed-term contracts). ${ }^{9}$ While casual employees in Australia are not necessarily dissatisfied with their jobs overall (see Buddelmeyer et al. 2015), they are

\footnotetext{
${ }^{9}$ Fixed-term contract employment arrangements are also common in Australia, though are less pervasive than in Germany; $8.2 \%$ of our HILDA Survey sample are employees who report that they are employed on a fixed-term contract.
} 
much more likely to be working fewer hours than desired (34\% of casual employees in our HILDA Survey sample are measured as underemployed compared with just 9\% of employees on a permanent or ongoing contract). But perhaps more importantly, casual employment by definition is associated with relatively high job insecurity - in effect, casual workers can be dismissed at any time with minimal notice. And indeed, the HILDA Survey data confirm that satisfaction with job security is markedly lower among casual employees than other employees (Green, Kler and Leeves 2010). This insecurity is expected to be a source of considerable stress, and hence lower mental health scores. That said, previous research into the effects of casual employment on mental health using the HILDA Survey data has been unable to find evidence for a causal link (Richardson, Lester and Zhang 2012; LaMontagne et al. 2014).

More striking than the differences across the two country samples, however, are the similarities. As we have emphasised, in both countries overemployment is negatively associated with psychological well-being, and the magnitude of this association is very similar. This was unexpected. Our expectation was that the effects of overemployment would be less pronounced in Germany, in part because we expected, as a result of the European Working Time Directive (which sets a notional maximum work week of 48 hours), the incidence of long hours of work to be relatively low in Germany. But this was not what was found. But why should the mental health of German workers be more responsive to overemployment than Australian workers? One possibility is that social norms in Germany (which may be affected by policies such as the Working Time Directive) may be less consistent with a long hours culture, which in turn may be conducive to greater levels of jobrelated stress. 


\section{REFERENCES}

Andersen, Hanfried H., Axel Mühlbacher, Matthias Nübling, Jürgen Schupp, and Gert G. Wagner. 2007. “Computation of Standard Values for Physical and Mental Health Scale Scores Using the SOEP Version of SF-12v2.” Schmollers Jahrbuch: Journal of Applied Social Science Studies, Vol. 127, No. 1, pp. 171-182.

Anderson, Sarah, and Anthony H. Winefield. 2011. “The Impact of Underemployment on Psychological Health, Physical Health, and Work Attitudes.” In Douglas C. Maynard and

Daniel C. Feldman (eds), Underemployment: Psychological, Economic, and Social Challenges, pp. 165-186. New York: Springer.

Angrave, David, and Andy Charlwood. 2015. "What is the Relationship Between Long Working Hours, Over-employment, Under-employment and the Subjective Well-being of Workers? Longitudinal Evidence from the UK.” Human Relations, Vol. 68, No. 9, pp. 1491-1515.

Bell, David, Steffen Otterbach, and Alfonso Sousa-Poza. 2012. “Work Hours Constraints and Health.” Annals of Economics and Statistics, Nos 105/106, pp. 35-54.

Bell, Linda A., and Richard B. Freeman. 1995. “The Incentive for Working Hard: Explaining Hours Worked Differences in the U.S. and Germany.” Labour Economics, Vol. 8, No. 2, pp. 181-202.

Buddelmeyer, Hielke, Duncan McVicar, and Mark Wooden. 2015 "Non-Standard “Contingent” Employment and Job Satisfaction: A Panel Data Analysis.” Industrial Relations: A Journal of Economy and Society, Vol. 54, No. 2, pp. 256-275.

Cernat, Alexandru, Mick Couper, and Mary Beth Ofstedal. 2015. "Estimation of Mode Effects in the Health and Retirement Study using Measurement Models.” ISER Working Paper Series No. 2015-19. Colchester (UK): Institute for Social and Economic Research, University of Essex. 
Cornelißen, Thomas. 2009. "The Interaction of Job Satisfaction, Job Search, and Job Changes: An Empirical Investigation with German Panel Data.” Journal of Happiness Studies, Vol. 10, No. 3, pp. 367-384.

Dooley, David, JoAnn Prause, and Kathleen A. Ham-Rowbottom. 2000. "Underemployment and Depression: Longitudinal Relationships.” Journal of Health and Social Behavior, Vol. 41, No. 4, pp. 421-436.

Edwards, Jeffrey R. 1991. “Person-Job Fit: A Conceptual Integration, Literature Review, and Methodological Critique.” In Cary L. Cooper and Ivan T. Robertson (eds), International Review of Industrial and Organizational Psychology, 1991, Vol. 6, pp. 283-357. Chichester (UK): John Wiley and Sons.

Friedland, Daniel S., and Richard H. Price. 2003. "Underemployment: Consequences for the Health and Well-being of Workers.” American Journal of Community Psychology, Vol. 32, Nos. 1/2, pp. 33-45.

Green, Colin, Parvinder Kler, and Gareth Leeves. 2010. "Flexible Contract Workers in Inferior Jobs: Reappraising the Evidence.” British Journal of Industrial Relations, Vol. 48, No. 3, pp. 605-629.

Green, Francis, and Nicholas Tsitsianis. 2005. “An Investigation of National Trends in Job Satisfaction in Britain and Germany.” British Journal of Industrial Relations, Vol. 43, No. 3, pp. 401-429.

Kristof, Amy L. 1996. "Person-Organization Fit: An Integrative Review of its Conceptualizations, Measurement, and Implications.” Personnel Psychology, Vol. 49, No. 1, pp. 1-49.

Kugler, Franziska, Andrea Wiencierz, and Christoph Wunder. 2014. "Working Hours Mismatch and Well-being: Comparative Evidence from Australian and German Panel 
Data.” LASER Discussion Paper No. 82. Nuremberg: Labor and Socio-Economic Research Center, University of Erlangen-Nuremberg.

LaMontagne, Anthony D., Allison Milner, Lauren Krnjacki, Anne M. Kavanaugh, Tony A. Blakely, and Rebecca Bentley. 2014. "Employment Arrangements and Mental Health in a Cohort of Working Australians: Are Transitions from Permanent to Temporary Employment Associated with Changes in Mental Health?” American Journal of Epidemiology, Vol. 179, No. 12, pp. 1467-1476.

Lyons, Ronan A., Kathie Wareham, Malcolm Lucas, David Price, John Williams, and Hayley A. Hutchings. 1999. "SF-36 Scores Vary by Method of Administration: Implications for Study Design.” Journal of Public Health, Vol. 21, No. 1, pp. 41-45.

Prause, JoAnn, and David Dooley. 1997. "Effect of Underemployment on School-Leavers’ Self-Esteem.” Journal of Adolescence, Vol. 20, No. 3, pp. 243-260.

Richardson, Sue, Laurence Lester, and Guangyu Zhang. 2012. “Are Casual and Contract Terms of Employment Hazardous for Mental Health in Australia?“ Journal of Industrial Relations, Vol.54, No. 5, pp. 557-578.

Robone, Silvana, Andrew M. Jones, and Nigel Rice. 2011. “Contractual Conditions, Working Conditions and their Impact on Health and Well-being.” European Journal of Health Economics, Vol. 12, No. 5, pp. 429-444.

Schwarze, Johannes. 1995. “Simulating German Income and Social Security Tax Payments using the GSOEP.” Cross-National Studies in Aging, Program Project Paper No. 19. AllUniversity Gerontology Center, Maxwell School of Citizenship and Public Affairs, Syracuse University (NY).

Wagner, Gert G., Joachim R. Frick and Jürgen Schupp. 2007. “The German Socio-Economic Panel Study (SOEP) - Scope, Evolution and Enhancements.” Schmollers Jahrbuch: Journal of Applied Social Science Studies, Vol. 127, No. 1, pp. 139-169. 
Watson, Nicole, and Mark Wooden. 2012. “The HILDA Survey: A Case Study in the Design and Development of a Successful Household Panel Study.” Longitudinal and Life Course Studies, Vol. 3, No. 3, pp. 369-381.

Watson, Nicole, and Mark Wooden. 2014. "Re-engaging with Survey Non-respondents: Evidence from Three Household Panels.” Journal of the Royal Statistical Society: Series A (Statistics in Society), Vol. 77, No. 2, pp. 499-522.

Wilkins, Roger. 2014. "Derived Income Variables in the HILDA Survey Data: The HILDA Survey Income Model.” HILDA Project Technical Paper Series No. 1/14. Melbourne: Melbourne Institute of Applied Economic and Social Research, University of Melbourne.

Wooden, Mark, Diana Warren, and Robert Drago. 2009. “Working Time Mismatch and Subjective Well-being.” British Journal of Industrial Relations, Vol. 47, No. 1, pp. 147179.

Wooldridge, Jeffrey M. 2005. "Simple Solutions to the Initial Conditions Problem in Dynamic, Nonlinear Panel Data Models with Unobserved Heterogeneity.” Journal of Applied Econometrics, Vol. 20, No. 1, pp. 39-54.

Wunder, Christoph, and Heineck, Guido. 2013. "Working Time Preferences, Hours Mismatch and Well-being of Couples: Are there Spillovers?” Labour Economics, Vol. 24, pp. 244-252. 
Table 1. Working-time Mismatch by Usual Weekly Hours Worked and Sex, HILDA Survey and SOEP Samples Compared (\% of employed persons aged 17 to 64)

\begin{tabular}{|c|c|c|c|c|}
\hline \multirow{2}{*}{$\begin{array}{l}\text { Usual weekly } \\
\text { hours worked }\end{array}$} & \multicolumn{3}{|c|}{ Type of mismatch } & \multirow{2}{*}{$\begin{array}{c}\% \\
\text { distribution }\end{array}$} \\
\hline & Underemployed & Matched & Overemployed & \\
\hline \multicolumn{5}{|c|}{ HILDA Survey (Australia) } \\
\hline \multicolumn{5}{|c|}{ Men } \\
\hline$<20$ & 43.3 & 53.8 & 3.9 & 6.4 \\
\hline $20-34$ & 40.0 & 53.3 & 6.7 & 8.4 \\
\hline $35-40$ & 12.6 & 72.2 & 15.2 & 36.2 \\
\hline $41-49$ & 6.9 & 60.2 & 32.9 & 18.8 \\
\hline $50+$ & 3.0 & 44.6 & 52.4 & 30.2 \\
\hline Sub-total & 12.9 & 58.8 & 28.3 & 100.0 \\
\hline \multicolumn{5}{|l|}{ Women } \\
\hline$<20$ & 35.0 & 62.1 & 2.9 & 20.8 \\
\hline $20-34$ & 22.3 & 65.4 & 12.3 & 26.6 \\
\hline $35-40$ & 4.8 & 66.1 & 29.1 & 33.1 \\
\hline $41-49$ & 1.7 & 48.3 & 50.0 & 9.7 \\
\hline $50+$ & 1.1 & 32.6 & 66.4 & 9.8 \\
\hline Sub-total & 15.1 & 60.1 & 24.9 & 100.0 \\
\hline \multicolumn{5}{|c|}{ SOEP (Germany) } \\
\hline \multicolumn{5}{|c|}{ Men } \\
\hline$<20$ & 55.8 & 40.9 & 3.2 & 3.5 \\
\hline $20-34$ & 47.4 & 39.9 & 12.7 & 3.8 \\
\hline $35-40$ & 7.3 & 72.4 & 20.4 & 36.1 \\
\hline $41-49$ & 4.4 & 34.4 & 61.2 & 30.3 \\
\hline $50+$ & 2.2 & 15.5 & 82.3 & 26.3 \\
\hline Sub-total & 8.3 & 43.6 & 48.1 & 100.0 \\
\hline \multicolumn{5}{|l|}{ Women } \\
\hline$<20$ & 46.3 & 49.0 & 4.8 & 18.0 \\
\hline $20-34$ & 25.0 & 54.0 & 21.0 & 27.1 \\
\hline $35-40$ & 4.1 & 56.6 & 39.2 & 30.0 \\
\hline $41-49$ & 1.7 & 24.9 & 73.4 & 17.6 \\
\hline $50+$ & 1.0 & 9.2 & 89.8 & 7.5 \\
\hline Sub-total & 16.7 & 45.4 & 37.9 & 100.0 \\
\hline
\end{tabular}


Table 2. Fixed-effects Estimates of the Impact of Working-time Mismatch on Mental Health (SF-12): Specification I

\begin{tabular}{|c|c|c|c|c|c|c|c|c|}
\hline & \multicolumn{4}{|c|}{ SOEP (Germany) } & \multicolumn{4}{|c|}{ HILDA Survey (Australia) } \\
\hline & \multicolumn{2}{|c|}{ Men } & \multicolumn{2}{|c|}{ Women } & \multicolumn{2}{|c|}{ Men } & \multicolumn{2}{|c|}{ Women } \\
\hline & Coef. & $S E$ & Coef. & $S E$ & Coef. & $S E$ & Coef. & $S E$ \\
\hline Not in labor force & -0.341 & 0.278 & -0.314 & 0.265 & $-2.175^{* * *}$ & 0.374 & $-0.956^{* *}$ & 0.391 \\
\hline Unemployed & $-0.962 * * *$ & 0.321 & $-0.887 * * *$ & 0.317 & $-1.683 * * *$ & 0.417 & $-1.215^{* * *}$ & 0.468 \\
\hline \multicolumn{9}{|l|}{ Employed } \\
\hline < 35h: underemployed & $0.519 *$ & 0.31 & -0.122 & 0.237 & 0.201 & 0.288 & -0.319 & 0.251 \\
\hline$<35 \mathrm{~h}$ : matched & 0.371 & 0.359 & 0.118 & 0.222 & 0.369 & 0.265 & 0.025 & 0.209 \\
\hline <35h: overemployed & -0.145 & 0.702 & $-0.961 * * *$ & 0.291 & -0.249 & 0.652 & $-0.975 * * *$ & 0.358 \\
\hline 35-40h: underemployed & -0.348 & 0.321 & 0.207 & 0.528 & -0.277 & 0.311 & 0.209 & 0.556 \\
\hline 35-40h: overemployed & $-0.627 * * *$ & 0.214 & $-0.837 * * *$ & 0.222 & $-0.708 * * *$ & 0.272 & $-0.818 * * *$ & 0.255 \\
\hline 41-49h: underemployed & -0.260 & 0.453 & -0.109 & 0.986 & 0.449 & 0.514 & $2.834 *$ & 1.688 \\
\hline 41-49h: matched & $-0.608 * * *$ & 0.191 & $-0.563^{*}$ & 0.307 & 0.003 & 0.207 & 0.232 & 0.333 \\
\hline 41-49h: overemployed & $-1.202^{* * *}$ & 0.166 & $-1.565 * * *$ & 0.226 & $-0.651 * *$ & 0.258 & $-0.704 * *$ & 0.327 \\
\hline 50+ h: underemployed & -0.202 & 0.673 & -1.935 & 1.874 & -0.776 & 0.681 & -2.241 & 2.588 \\
\hline $50+$ h: matched & -0.319 & 0.296 & 0.080 & 0.748 & 0.044 & 0.22 & -0.285 & 0.411 \\
\hline 50+ h: overemployed & $-1.132 * * *$ & 0.189 & $-1.724 * * *$ & 0.303 & $-0.946 * * *$ & 0.218 & $-1.263 * * *$ & 0.326 \\
\hline Age: $17-24$ & 0.502 & 0.367 & 0.516 & 0.379 & $1.316^{* * *}$ & 0.415 & 0.495 & 0.432 \\
\hline Age: $25-34$ & 0.009 & 0.229 & 0.022 & 0.232 & $0.531 * *$ & 0.258 & 0.14 & 0.261 \\
\hline Age: $45-54$ & -0.279 & 0.195 & 0.164 & 0.206 & 0.319 & 0.235 & -0.099 & 0.25 \\
\hline Age: 55-64 & 0.239 & 0.319 & 0.473 & 0.333 & $1.209 * * *$ & 0.391 & 0.019 & 0.41 \\
\hline Married & $0.839 * * *$ & 0.211 & $0.788 * * *$ & 0.206 & $1.241 * * *$ & 0.211 & $1.368 * * *$ & 0.209 \\
\hline Number of children & -0.062 & 0.09 & -0.027 & 0.096 & -0.054 & 0.084 & -0.107 & 0.092 \\
\hline Disabled & $-1.564 * * *$ & 0.273 & $-1.985^{* * *}$ & 0.307 & $-2.168 * * *$ & 0.225 & $-2.734 * * *$ & 0.216 \\
\hline Ln real equivalized net h'hold income & $0.340 * *$ & 0.145 & $0.572 * * *$ & 0.137 & $0.266^{* *}$ & 0.126 & $0.443^{* * *}$ & 0.131 \\
\hline Constant & $47.520 * * *$ & 1.491 & $42.798 * * *$ & 1.404 & $47.768 * * *$ & 1.399 & $43.824 * * *$ & 1.441 \\
\hline Number of observations & \multicolumn{2}{|c|}{43,683} & \multicolumn{2}{|c|}{47,430} & \multicolumn{2}{|c|}{26,320} & \multicolumn{2}{|c|}{29,610} \\
\hline Number of groups & \multicolumn{2}{|c|}{15,267} & \multicolumn{2}{|c|}{16,311} & \multicolumn{2}{|c|}{8,974} & \multicolumn{2}{|c|}{9,639} \\
\hline $\mathrm{R}^{2}$ overall & \multicolumn{2}{|c|}{0.020} & \multicolumn{2}{|c|}{0.031} & \multicolumn{2}{|c|}{0.084} & \multicolumn{2}{|c|}{0.066} \\
\hline $\mathrm{R}^{2}$ within & \multicolumn{2}{|c|}{0.008} & \multicolumn{2}{|c|}{0.008} & \multicolumn{2}{|c|}{0.018} & \multicolumn{2}{|c|}{0.019} \\
\hline $\mathrm{R}^{2}$ between & \multicolumn{2}{|c|}{0.022} & \multicolumn{2}{|c|}{0.037} & \multicolumn{2}{|c|}{0.107} & \multicolumn{2}{|c|}{0.070} \\
\hline
\end{tabular}

Notes: The dependent variable is the SF-12 Mental Component Summary (MCS) score. All models include survey/time indicators and 2-digit ISCO occupation dummies.

* Statistically significant at the .10 level; ** at the .05 level; *** at the .01 level. 
Table 3. Fixed-effects Estimates of the Impact of Working-time Mismatch on Mental Health (SF-12): Specification II

\begin{tabular}{|c|c|c|c|c|c|c|c|c|}
\hline & \multicolumn{4}{|c|}{ SOEP (Germany) } & \multicolumn{4}{|c|}{ HILDA Survey (Australia) } \\
\hline & \multicolumn{2}{|c|}{ Men } & \multicolumn{2}{|c|}{ Women } & \multicolumn{2}{|c|}{ Men } & \multicolumn{2}{|c|}{ Women } \\
\hline & Coef. & SE & Coef. & SE & Coef. & SE & Coef. & SE \\
\hline Not in labor force & -0.309 & 0.272 & -0.365 & 0.250 & $-2.144 * * *$ & 0.372 & $-0.999 * *$ & 0.387 \\
\hline Unemployed & $-0.925^{* * *}$ & 0.317 & $-0.940 * * *$ & 0.304 & $-1.655^{* * *}$ & 0.417 & $-1.274^{* * *}$ & 0.465 \\
\hline \multicolumn{9}{|l|}{ Employed } \\
\hline$<35 \mathrm{~h}$ & 0.350 & 0.279 & 0.023 & 0.186 & $0.509 * *$ & 0.226 & 0.015 & 0.185 \\
\hline $41 h-49 h$ & $-0.564 * * *$ & 0.142 & $-0.631^{* * *}$ & 0.189 & -0.001 & 0.173 & 0.161 & 0.246 \\
\hline $50+\mathrm{h}$ & -0.183 & 0.195 & -0.245 & 0.307 & -0.122 & 0.190 & -0.339 & 0.294 \\
\hline Hours underemployed & -0.015 & 0.015 & 0.020 & 0.014 & $-0.035^{* * *}$ & 0.014 & $-0.036^{* *}$ & 0.015 \\
\hline Hours overemployed & $-0.064 * * *$ & 0.009 & $-0.092 * * *$ & 0.012 & $-0.037 * * *$ & 0.009 & $-0.048 * * *$ & 0.012 \\
\hline Age: $17-24$ & 0.488 & 0.367 & 0.526 & 0.378 & $1.284 * * *$ & 0.418 & 0.504 & 0.436 \\
\hline Age: $25-34$ & -0.006 & 0.229 & 0.026 & 0.231 & $0.529 * *$ & 0.259 & 0.146 & 0.263 \\
\hline Age: $45-54$ & -0.278 & 0.195 & 0.152 & 0.206 & 0.278 & 0.236 & -0.138 & 0.252 \\
\hline Age: $55-64$ & 0.244 & 0.318 & 0.447 & 0.333 & $1.147 * * *$ & 0.393 & 0.046 & 0.413 \\
\hline Married & $0.844 * * *$ & 0.211 & $0.802 * * *$ & 0.206 & $1.222 * * *$ & 0.213 & $1.324 * * *$ & 0.211 \\
\hline Number of children & -0.060 & 0.090 & -0.023 & 0.096 & -0.053 & 0.084 & -0.102 & 0.093 \\
\hline Disabled & $-1.566 * * *$ & 0.272 & $-1.984 * * *$ & 0.307 & $-2.173^{* * *}$ & 0.227 & $-2.743 * * *$ & 0.217 \\
\hline Ln real equivalized net h'hold income & $0.351 * *$ & 0.145 & $0.568 * * *$ & 0.137 & $0.251^{* *}$ & 0.127 & $0.444^{* * *}$ & 0.131 \\
\hline Constant & $47.379 * * *$ & 1.489 & $42.871 * * *$ & 1.401 & $47.883^{* * *}$ & 1.408 & $43.855^{* * *}$ & 1.450 \\
\hline Number of observations & \multicolumn{2}{|c|}{43,683} & \multicolumn{2}{|c|}{47,430} & \multicolumn{2}{|c|}{26,046} & \multicolumn{2}{|c|}{29,256} \\
\hline Number of groups & \multicolumn{2}{|c|}{15,267} & \multicolumn{2}{|c|}{16,311} & \multicolumn{2}{|c|}{8,923} & \multicolumn{2}{|c|}{9,588} \\
\hline $\mathrm{R}^{2}$ overall & \multicolumn{2}{|c|}{0.021} & \multicolumn{2}{|c|}{0.032} & \multicolumn{2}{|c|}{0.084} & \multicolumn{2}{|c|}{0.065} \\
\hline $\mathrm{R}^{2}$ within & \multicolumn{2}{|c|}{0.009} & \multicolumn{2}{|c|}{0.008} & \multicolumn{2}{|c|}{0.017} & \multicolumn{2}{|c|}{0.019} \\
\hline $\mathrm{R}^{2}$ between & \multicolumn{2}{|c|}{0.023} & \multicolumn{2}{|c|}{0.037} & \multicolumn{2}{|c|}{0.108} & \multicolumn{2}{|c|}{0.069} \\
\hline
\end{tabular}

Notes: The dependent variable is the SF-12 Mental Component Summary (MCS) score. All models include survey/time indicators and 2-digit ISCO occupation dummies.

* Statistically significant at the .10 level; ** at the .05 level; *** at the .01 level. 
Table 4. Correlated Random Effects Estimates of the Impact of Working-time Mismatch on Mental Health (SF-12): Specification I

\begin{tabular}{|c|c|c|c|c|c|c|c|c|}
\hline & \multicolumn{4}{|c|}{ SOEP (Germany) } & \multicolumn{4}{|c|}{ HILDA Survey (Australia) } \\
\hline & \multicolumn{2}{|c|}{ Men } & \multicolumn{2}{|c|}{ Women } & \multicolumn{2}{|c|}{ Men } & \multicolumn{2}{|c|}{ Women } \\
\hline & Coef. & SE & Coef. & SE & Coef. & SE & Coef. & $S E$ \\
\hline $\mathrm{MCS}_{\mathrm{t}-1}$ & $0.265 * * *$ & 0.007 & $0.269 * * *$ & 0.006 & $0.181^{* * *}$ & 0.009 & $0.247 * * *$ & 0.008 \\
\hline $\mathrm{MCS}_{\text {initial }}$ & $0.247 * * *$ & 0.007 & $0.232^{* * *}$ & 0.007 & $0.312 * * *$ & 0.010 & $0.247 * * *$ & 0.008 \\
\hline Not in labor force & 0.160 & 0.456 & 0.717 & 0.558 & $-1.512 * * *$ & 0.381 & $-1.359 * * *$ & 0.363 \\
\hline Unemployed & -0.109 & 0.496 & -0.090 & 0.594 & $-1.390 * * *$ & 0.463 & $-1.977 * * *$ & 0.483 \\
\hline \multicolumn{9}{|l|}{ Employed } \\
\hline < 35h: underemployed & -0.129 & 0.311 & -0.300 & 0.227 & -0.300 & 0.326 & $-0.534 * *$ & 0.270 \\
\hline$<35 \mathrm{~h}$ : matched & -0.254 & 0.356 & 0.090 & 0.207 & 0.446 & 0.280 & $0.367^{*}$ & 0.210 \\
\hline <35h: overemployed & $-1.255^{*}$ & 0.747 & $-1.429 * * *$ & 0.286 & -0.749 & 0.709 & $-1.149 * * *$ & 0.386 \\
\hline 35-40h: underemployed & $-0.904 * *$ & 0.355 & 0.033 & 0.568 & -0.303 & 0.341 & -0.555 & 0.637 \\
\hline 35-40h: overemployed & $-1.104 * * *$ & 0.225 & $-1.301 * * *$ & 0.232 & $-0.985 * * *$ & 0.288 & $-0.834 * * *$ & 0.274 \\
\hline 41-49h: underemployed & $-1.362 * * *$ & 0.482 & -1.051 & 1.118 & 0.383 & 0.608 & 1.888 & 2.039 \\
\hline 41-49h: matched & $-0.841^{* * *}$ & 0.197 & -0.436 & 0.323 & 0.111 & 0.222 & 0.611 & 0.373 \\
\hline 41-49h: overemployed & $-1.565 * * *$ & 0.167 & $-1.857 * * *$ & 0.228 & -0.338 & 0.279 & $-0.726 * *$ & 0.358 \\
\hline $50+$ h: underemployed & -0.922 & 0.705 & $-5.509 * * *$ & 1.934 & -1.096 & 0.745 & -3.470 & 2.903 \\
\hline 50+ h: matched & -0.419 & 0.304 & 0.099 & 0.818 & 0.243 & 0.225 & 0.097 & 0.441 \\
\hline 50+ h: overemployed & $-1.492 * * *$ & 0.171 & $-1.733 * * *$ & 0.290 & $-0.909 * * *$ & 0.216 & $-1.280 * * *$ & 0.333 \\
\hline Age: $17-24$ & 0.459 & 0.479 & -0.265 & 0.497 & $1.159 * *$ & 0.536 & 0.766 & 0.563 \\
\hline Age: $25-34$ & 0.220 & 0.308 & -0.226 & 0.307 & 0.417 & 0.340 & 0.140 & 0.349 \\
\hline Age: $45-54$ & -0.180 & 0.250 & 0.114 & 0.265 & -0.088 & 0.300 & -0.066 & 0.327 \\
\hline Age: 55-64 & 0.104 & 0.402 & 0.260 & 0.418 & 0.438 & 0.484 & -0.198 & 0.523 \\
\hline Married & $0.463 *$ & 0.279 & $0.625 * *$ & 0.273 & $1.279 * * *$ & 0.277 & $1.509 * * *$ & 0.280 \\
\hline Number of children & -0.120 & 0.123 & -0.004 & 0.132 & $-0.293 * *$ & 0.114 & -0.067 & 0.128 \\
\hline Disabled & $-1.823 * * *$ & 0.351 & $-1.833 * * *$ & 0.392 & $-2.319 * * *$ & 0.280 & $-2.489 * * *$ & 0.276 \\
\hline Ln real equivalized net h'hold income & $0.362 *$ & 0.190 & $0.621 * * *$ & 0.177 & $0.412 * *$ & 0.161 & $0.573 * * *$ & 0.174 \\
\hline Constant & $13.318^{* * *}$ & 1.497 & $12.820 * * *$ & 1.450 & $15.387 * * *$ & 2.345 & $17.030 * * *$ & 2.157 \\
\hline Number of observations & \multicolumn{2}{|c|}{28,428} & \multicolumn{2}{|c|}{30,937} & \multicolumn{2}{|c|}{16,209} & \multicolumn{2}{|c|}{18,682} \\
\hline Number of groups & \multicolumn{2}{|c|}{9,681} & \multicolumn{2}{|c|}{10,285} & \multicolumn{2}{|c|}{5,417} & \multicolumn{2}{|c|}{6,025} \\
\hline $\mathrm{R}^{2}$ overall & \multicolumn{2}{|c|}{0.284} & \multicolumn{2}{|c|}{0.274} & \multicolumn{2}{|c|}{0.336} & \multicolumn{2}{|c|}{0.330} \\
\hline $\mathrm{R}^{2}$ within & \multicolumn{2}{|c|}{0.010} & \multicolumn{2}{|c|}{0.009} & \multicolumn{2}{|c|}{0.002} & \multicolumn{2}{|c|}{0.003} \\
\hline $\mathrm{R}^{2}$ between & \multicolumn{2}{|c|}{0.446} & \multicolumn{2}{|c|}{0.439} & \multicolumn{2}{|c|}{0.446} & \multicolumn{2}{|c|}{0.498} \\
\hline
\end{tabular}

Notes: The dependent variable is the SF-12 Mental Component Summary (MCS) score. All models include survey/time indicators and 2-digit ISCO occupation dummies.

* Statistically significant at the .10 level; ** at the .05 level; *** at the .01 level. 
Table 5.Correlated Random Effects Estimates of the Impact of Working-time Mismatch on Mental Health (SF-12): Specification II

\begin{tabular}{|c|c|c|c|c|c|c|c|c|}
\hline & \multicolumn{4}{|c|}{ SOEP (Germany) } & \multicolumn{4}{|c|}{ HILDA Survey (Australia) } \\
\hline & \multicolumn{2}{|c|}{ Men } & \multicolumn{2}{|c|}{ Women } & \multicolumn{2}{|c|}{ Men } & \multicolumn{2}{|c|}{ Women } \\
\hline & Coef. & $S E$ & Coef. & $S E$ & Coef. & $S E$ & Coef. & $S E$ \\
\hline $\mathrm{MCS}_{\mathrm{t}-1}$ & $0.264 * * *$ & 0.007 & $0.270 * * *$ & 0.006 & $0.181 * * *$ & 0.009 & $0.246 * * *$ & 0.008 \\
\hline $\mathrm{MCS}_{\text {initial }}$ & $0.247 * * *$ & 0.007 & $0.231 * * *$ & 0.007 & $0.313^{* * *}$ & 0.010 & $0.248 * * *$ & 0.008 \\
\hline Not in labor force & 0.355 & 0.453 & 0.736 & 0.552 & $-1.461 * * *$ & 0.379 & $-1.406^{* * *}$ & 0.356 \\
\hline Unemployed & 0.083 & 0.493 & -0.063 & 0.589 & $-1.291 * * *$ & 0.462 & $-2.030 * * *$ & 0.479 \\
\hline \multicolumn{9}{|l|}{ Employed } \\
\hline$<35 h$ & $0.755^{* *}$ & 0.339 & 0.346 & 0.229 & $0.752 * * *$ & 0.286 & 0.130 & 0.230 \\
\hline $41 h-49 h$ & $-0.537 * * *$ & 0.178 & $-0.466 * *$ & 0.237 & 0.262 & 0.214 & 0.330 & 0.313 \\
\hline $50+h$ & -0.039 & 0.238 & 0.023 & 0.375 & 0.305 & 0.235 & -0.372 & 0.368 \\
\hline Hours underemployed & 0.012 & 0.015 & $0.026 *$ & 0.014 & $-0.055 * * *$ & 0.015 & $-0.067 * * *$ & 0.017 \\
\hline Hours overemployed & $-0.086^{* * *}$ & 0.009 & $-0.127 * * *$ & 0.012 & $-0.049 * * *$ & 0.009 & $-0.064 * * *$ & 0.012 \\
\hline Age: $17-24$ & 0.440 & 0.479 & -0.263 & 0.497 & $1.112^{* *}$ & 0.539 & 0.751 & 0.568 \\
\hline Age: $25-34$ & 0.192 & 0.308 & -0.213 & 0.307 & 0.390 & 0.342 & 0.142 & 0.351 \\
\hline Age: $45-54$ & -0.181 & 0.250 & 0.108 & 0.265 & -0.111 & 0.301 & -0.065 & 0.329 \\
\hline Age: 55-64 & 0.118 & 0.401 & 0.239 & 0.418 & 0.377 & 0.486 & -0.240 & 0.526 \\
\hline Married & $0.485^{*}$ & 0.279 & $0.612 * *$ & 0.274 & $1.258 * * *$ & 0.278 & $1.478 * * *$ & 0.282 \\
\hline Number of children & -0.122 & 0.123 & -0.016 & 0.133 & $-0.288 * *$ & 0.115 & -0.060 & 0.130 \\
\hline Disabled & $-1.822 * * *$ & 0.351 & $-1.818^{* * *}$ & 0.392 & $-2.264 * * *$ & 0.281 & $-2.526 * * *$ & 0.278 \\
\hline Ln real equivalized net h'hold income & $0.381 * *$ & 0.190 & $0.637 * * *$ & 0.177 & $0.400^{* *}$ & 0.162 & $0.556^{* * *}$ & 0.175 \\
\hline Constant & $13.356 * * *$ & 1.508 & $12.831^{* * *}$ & 1.449 & $15.093^{* * *}$ & 2.368 & $17.543^{* * *}$ & 2.171 \\
\hline Number of observations & \multicolumn{2}{|c|}{28,428} & \multicolumn{2}{|c|}{30,937} & \multicolumn{2}{|c|}{16,066} & \multicolumn{2}{|c|}{18,476} \\
\hline Number of groups & \multicolumn{2}{|c|}{9,681} & \multicolumn{2}{|c|}{10,285} & \multicolumn{2}{|c|}{5,402} & \multicolumn{2}{|c|}{6,009} \\
\hline $\mathrm{R}^{2}$ overall & \multicolumn{2}{|c|}{0.285} & \multicolumn{2}{|c|}{0.275} & \multicolumn{2}{|c|}{0.337} & \multicolumn{2}{|c|}{0.330} \\
\hline $\mathrm{R}^{2}$ within & \multicolumn{2}{|c|}{0.009} & \multicolumn{2}{|c|}{0.009} & \multicolumn{2}{|c|}{0.002} & \multicolumn{2}{|c|}{0.003} \\
\hline $\mathrm{R}^{2}$ between & \multicolumn{2}{|c|}{0.447} & \multicolumn{2}{|c|}{0.441} & \multicolumn{2}{|c|}{0.448} & \multicolumn{2}{|c|}{0.497} \\
\hline
\end{tabular}

Notes: The dependent variable is the SF-12 Mental Component Summary (MCS) score. All models include survey/time indicators and 2-digit ISCO occupation dummies.

* Statistically significant at the .10 level; ** at the .05 level; *** at the .01 level. 
Appendix Table A1. Descriptive Statistics: Means (and Standard Deviations in Parentheses)

\begin{tabular}{|c|c|c|c|c|c|c|}
\hline \multirow[t]{2}{*}{ Variable } & \multicolumn{2}{|c|}{ SOEP } & \multicolumn{2}{|c|}{ HILDA Survey (6 waves) } & \multicolumn{2}{|c|}{ HILDA Survey (13 waves) } \\
\hline & Men & Women & Men & Women & Men & Women \\
\hline Mental Component Summary (MCS) & $50.717(9.42)$ & $48.847(10.07)$ & $50.671(9.29)$ & $49.006(10.09)$ & $50.652(9.28)$ & $49.087(10.06)$ \\
\hline Not in the labour force & $0.172(0.38)$ & $0.294(0.46)$ & $0.128(0.33)$ & $0.265(0.46)$ & $0.130(0.34)$ & $0.268(0.44)$ \\
\hline Unemployed & $0.051(0.22)$ & $0.049(0.22)$ & $0.040(0.20)$ & $0.036(0.19)$ & $0.041(0.20)$ & $0.036(0.19)$ \\
\hline \multicolumn{7}{|c|}{$\begin{array}{l}\text { Employed (Usual weekly hours x mismatch } \\
\text { status) }\end{array}$} \\
\hline < 35h: underemployed & $0.029(0.17)$ & $0.097(0.30)$ & $0.050(0.22)$ & $0.091(0.29)$ & $0.052(0.22)$ & $0.093(0.29)$ \\
\hline <35h: unconstrained & $0.022(0.15)$ & $0.151(0.36)$ & $0.068(0.25)$ & $0.216(0.41)$ & $0.068(0.25)$ & $0.214(0.41)$ \\
\hline <35h: overemployed & $0.005(0.07)$ & $0.042(0.20)$ & $0.006(0.08)$ & $0.028(0.17)$ & $0.006(0.08)$ & $0.028(0.16)$ \\
\hline 35-40h: underemployed & $0.020(0.14)$ & $0.008(0.09)$ & $0.036(0.19)$ & $0.010(0.10)$ & $0.036(0.19)$ & $0.010(0.10)$ \\
\hline 35-40h: unconstrained & $0.201(0.40)$ & $0.110(0.31)$ & $0.219(0.41)$ & $0.152(0.36)$ & $0.217(0.41)$ & $0.150(0.36)$ \\
\hline 35-40h: overemployed & $0.057(0.23)$ & $0.076(0.26)$ & $0.047(0.21)$ & $0.067(0.25)$ & $0.046(0.21)$ & $0.068(0.25)$ \\
\hline 41-49h: underemployed & $0.010(0.10)$ & $0.002(0.04)$ & $0.011(0.10)$ & $0.001(0.03)$ & $0.010(0.10)$ & $0.001(0.04)$ \\
\hline 41-49h: unconstrained & $0.080(0.27)$ & $0.028(0.17)$ & $0.096(0.29)$ & $0.032(0.18)$ & $0.096(0.30)$ & $0.034(0.18)$ \\
\hline 41-49h: overemployed & $0.143(0.35)$ & $0.083(0.28)$ & $0.053(0.22)$ & $0.034(0.18)$ & $0.051(0.22)$ & $0.034(0.18)$ \\
\hline 50+ h: underemployed & $0.004(0.07)$ & $0.000(0.02)$ & $0.007(0.08)$ & $0.001(0.02)$ & $0.007(0.08)$ & $0.001(0.02)$ \\
\hline 50+ h: unconstrained & $0.031(0.17)$ & $0.004(0.07)$ & $0.110(0.31)$ & $0.022(0.15)$ & $0.110(0.31)$ & $0.022(0.15)$ \\
\hline 50+ h: overemployed & $0.166(0.37)$ & $0.043(0.20)$ & $0.131(0.34)$ & $0.045(0.21)$ & $0.129(0.34)$ & $0.044(0.21)$ \\
\hline Hours underemployed (if > 0) & $8.726(9.04)$ & 8.987 (7.28) & $11.738(7.90)$ & $11.070(7.14)$ & $11.856(8.10)$ & $11.106(7.01)$ \\
\hline Hours overemployed (if $>0$ ) & $9.325(7.64)$ & $8.418(6.76)$ & $14.073(9.15)$ & $12.904(7.93)$ & $14.001(9.08)$ & $12.937(8.05)$ \\
\hline \multicolumn{7}{|l|}{ Age } \\
\hline $17-24$ & $0.137(0.34)$ & $0.129(0.34)$ & $0.175(0.38)$ & $0.172(0.38)$ & $0.174(0.38)$ & $0.172(0.38)$ \\
\hline $25-34$ & $0.164(0.37)$ & $0.175(0.38)$ & $0.197(0.40)$ & $0.202(0.40)$ & $0.199(0.40)$ & $0.204(0.40)$ \\
\hline $35-44$ & $0.240(0.43)$ & $0.242(0.43)$ & $0.229(0.42)$ & $0.237(0.43)$ & $0.229(0.42)$ & $0.235(0.42)$ \\
\hline $45-54$ & $0.244(0.43)$ & $0.250(0.43)$ & $0.226(0.42)$ & $0.221(0.41)$ & $0.225(0.42)$ & $0.221(0.41)$ \\
\hline $55-64$ & $0.214(0.41)$ & $0.204(0.40)$ & $0.173(0.38)$ & $0.169(0.38)$ & $0.174(0.38)$ & $0.168(0.37)$ \\
\hline Married & $0.579(0.49)$ & $0.595(0.49)$ & $0.661(0.49)$ & $0.654(0.48)$ & $0.662(0.47)$ & $0.655(0.48)$ \\
\hline Number of children & $0.607(0.94)$ & $0.639(0.94)$ & $0.684(1.06)$ & $0.758(1.09)$ & $0.684(1.06)$ & 0.758 (1.09) \\
\hline Disabled & $0.096(0.30)$ & $0.078(0.27)$ & $0.128(0.33)$ & $0.143(0.35)$ & $0.133(0.34)$ & $0.146(0.35)$ \\
\hline Real net household income (000s) & $47.127(46.15)$ & $45.003(44.85)$ & $90.339(59.36)$ & $86.697(59.16)$ & $90.476(61.21)$ & $86.965(60.39)$ \\
\hline Ln real equivalized net h'hold income & $10.090(0.55)$ & $10.032(0.58)$ & $10.736(0.59)$ & $10.675(0.61)$ & $10.735(0.59)$ & $10.676(0.61)$ \\
\hline
\end{tabular}




\section{Survey year}

Year 2001

Year 2002

Year 2003

Year 2004

Year 2005

Year 2006

Year 2007

Year 2008

Year 2009

Year 2010

Year 2011

Year 2012

Year 2013

\begin{tabular}{|c|c|c|c|c|c|}
\hline & & & & $0.081(0.27)$ & $0.080(0.27)$ \\
\hline \multirow[t]{2}{*}{$0.203(0.40)$} & $0.194(0.40)$ & $0.165(0.37)$ & $0.162(0.37)$ & $0.074(0.26)$ & $0.073(0.26)$ \\
\hline & & & & $0.072(0.26)$ & $0.072(0.26)$ \\
\hline \multirow[t]{2}{*}{$0.180(0.38)$} & 0.177 (0.38) & $0.156(0.36)$ & $0.156(0.36)$ & $0.070(0.26)$ & $0.070(0.26)$ \\
\hline & & & & $0.070(0.26)$ & $0.071(0.26)$ \\
\hline \multirow[t]{2}{*}{$0.175(0.38)$} & $0.175(0.38)$ & $0.155(0.36)$ & $0.155(0.36)$ & $0.070(0.25)$ & $0.070(0.25)$ \\
\hline & & & & $0.068(0.25)$ & $0.069(0.25)$ \\
\hline \multirow[t]{2}{*}{$0.151(0.36)$} & $0.152(0.36)$ & $0.151(0.36)$ & $0.152(0.36)$ & $0.068(0.25)$ & $0.068(0.25)$ \\
\hline & & & & $0.070(0.26)$ & $0.070(0.26)$ \\
\hline \multirow[t]{2}{*}{$0.142(0.35)$} & $0.144(0.35)$ & $0.165(0.37)$ & $0.164(0.37)$ & $0.074(0.26)$ & $0.074(0.26)$ \\
\hline & & & & $0.095(0.29)$ & $0.094(0.29)$ \\
\hline \multirow[t]{2}{*}{$0.150(0.36)$} & 0.158 (0.37) & $0.207(0.41)$ & $0.211(0.41)$ & $0.093(0.29)$ & $0.095(0.29)$ \\
\hline & & & & $0.093(0.29)$ & $0.094(0.29)$ \\
\hline
\end{tabular}


Appendix Table A2. Impact of Working-time Mismatch on Mental Health (SF-12): Specification I, HILDA Survey (Australia), 2001-2013

(13 waves)

\begin{tabular}{|c|c|c|c|c|c|c|c|c|}
\hline & \multicolumn{4}{|c|}{ Fixed-effects } & \multicolumn{4}{|c|}{ Correlated Random Effects } \\
\hline & \multicolumn{2}{|l|}{ Men } & \multicolumn{2}{|c|}{ Women } & \multicolumn{2}{|c|}{ Men } & \multicolumn{2}{|c|}{ Women } \\
\hline & Coef & $S E$ & Coef & $S E$ & Coef & $S E$ & Coef & $S E$ \\
\hline $\mathrm{MCS}_{\mathrm{t}-1}$ & & & & & $0.294 * * *$ & 0.005 & $0.333 * * *$ & 0.004 \\
\hline $\mathrm{MCS}_{\text {initial }}$ & & & & & $0.242 * * *$ & 0.006 & $0.216^{* * *}$ & 0.005 \\
\hline Not in labor force & $-1.664 * * *$ & 0.229 & $-1.259 * * *$ & 0.244 & $-1.517 * * *$ & 0.228 & $-1.178 * * *$ & 0.217 \\
\hline Unemployed & $-1.339 * * *$ & 0.252 & $-1.160 * * *$ & 0.289 & $-1.397 * * *$ & 0.267 & $-1.438 * * *$ & 0.285 \\
\hline$<35$ h: underemployed & $-0.338 * *$ & 0.172 & $-0.332 * *$ & 0.153 & $-0.467 * *$ & 0.182 & $-0.470 * * *$ & 0.158 \\
\hline <35h: matched & 0.007 & 0.162 & -0.099 & 0.129 & 0.299* & 0.165 & 0.038 & 0.127 \\
\hline <35h: overemployed & $-0.920 * *$ & 0.411 & $-1.002^{* * *}$ & 0.222 & $-1.043^{* *}$ & 0.436 & $-1.207^{* * *}$ & 0.233 \\
\hline 35-40h: underemployed & -0.067 & 0.186 & -0.407 & 0.338 & $-0.407 * *$ & 0.203 & $-0.634^{*}$ & 0.376 \\
\hline 35-40h: overemployed & $-0.878 * * *$ & 0.166 & $-0.702 * * *$ & 0.155 & $-1.128 * * *$ & 0.174 & $-0.780 * * *$ & 0.164 \\
\hline 41-49h: underemployed & $0.575 *$ & 0.323 & -0.265 & 0.895 & 0.587 & 0.369 & -0.780 & 1.054 \\
\hline 41-49h: matched & -0.001 & 0.127 & 0.218 & 0.202 & 0.020 & 0.133 & 0.216 & 0.218 \\
\hline 41-49h: overemployed & $-0.507 * * *$ & 0.162 & $-0.675^{* * *}$ & 0.202 & $-0.618 * * *$ & 0.170 & $-0.917^{* * *}$ & 0.215 \\
\hline 50+ h: underemployed & $-0.860 * *$ & 0.404 & -0.427 & 1.491 & $-1.198 * * *$ & 0.439 & -1.817 & 1.645 \\
\hline 50+ h: matched & 0.122 & 0.136 & 0.100 & 0.250 & 0.177 & 0.135 & 0.370 & 0.262 \\
\hline 50+ h: overemployed & $-0.895 * * *$ & 0.135 & $-1.193 * * *$ & 0.203 & $-0.871 * * *$ & 0.132 & $-1.343 * * *$ & 0.202 \\
\hline Age: $17-24$ & $1.107 * * *$ & 0.266 & 0.499* & 0.273 & $0.686 * *$ & 0.318 & 0.540 & 0.330 \\
\hline Age: $25-34$ & 0.236 & 0.164 & $0.337 * *$ & 0.166 & 0.070 & 0.197 & 0.243 & 0.202 \\
\hline Age: $45-54$ & $0.272 *$ & 0.151 & -0.219 & 0.159 & 0.012 & 0.177 & -0.297 & 0.191 \\
\hline Age: 55-64 & $1.107 * * *$ & 0.251 & -0.163 & 0.262 & $0.612^{* *}$ & 0.292 & -0.273 & 0.312 \\
\hline Married & $1.399 * * *$ & 0.132 & $1.325 * * *$ & 0.130 & $0.890 * * *$ & 0.161 & $0.833 * * *$ & 0.161 \\
\hline Number of children & 0.072 & 0.052 & $-0.098 *$ & 0.057 & -0.105 & 0.065 & $-0.207 * * *$ & 0.071 \\
\hline Disabled & $-2.014 * * *$ & 0.134 & $-2.397 * * *$ & 0.130 & $-1.758 * * *$ & 0.159 & $-2.128 * * *$ & 0.157 \\
\hline Ln real equivalized net h'hold income & 0.101 & 0.078 & $0.402 * * *$ & 0.081 & 0.093 & 0.093 & $0.281 * * *$ & 0.099 \\
\hline Constant & $49.104 * * *$ & 0.865 & $44.585^{* * *}$ & 0.898 & $14.420 * * *$ & 1.344 & $16.593^{* * *}$ & 1.221 \\
\hline Number of observations & 58,413 & & 65,89 & & 43,66 & & 50,1 & \\
\hline Number of groups & 10,80 & & 11,57 & & 8,240 & & 8,9 & \\
\hline $\mathrm{R}^{2}$ overall & 0.083 & & 0.05 & & 0.378 & & 0.3 & \\
\hline $\mathrm{R}^{2}$ within & 0.015 & & 0.015 & & 0.00 & & 0.0 & \\
\hline $\mathrm{R}^{2}$ between & 0.118 & & 0.06 & & 0.56 & & 0.5 & \\
\hline
\end{tabular}

Notes: The dependent variable is the SF-12 Mental Component Summary (MCS) score. All estimates include survey/time indicators and 2-digit ISCO occupation dummies.

*Statistically significant at the .10 level; ** at the .05 level; *** at the .01 level. 
Appendix Table A3. Impact of Working-time Mismatch on Mental Health (SF-12): Specification II, HILDA Survey (Australia), $2001-2013$

(13 waves)

\begin{tabular}{|c|c|c|c|c|c|c|c|c|}
\hline & \multicolumn{4}{|c|}{ Fixed-effects } & \multicolumn{4}{|c|}{ Correlated Random Effects } \\
\hline & \multicolumn{2}{|l|}{ Men } & \multicolumn{2}{|c|}{ Women } & \multicolumn{2}{|l|}{ Men } & \multicolumn{2}{|c|}{ Women } \\
\hline & Coef & $S E$ & Coef & $S E$ & Coef & $S E$ & Coef & $S E$ \\
\hline $\mathrm{MCS}_{\mathrm{t}-1}$ & & & & & $0.293^{* * *}$ & 0.005 & $0.328 * * *$ & 0.004 \\
\hline $\mathrm{MCS}_{\text {initial }}$ & & & & & $0.242^{* * *}$ & 0.006 & $0.219 * * *$ & 0.005 \\
\hline Not in labor force & $-1.631 * * *$ & 0.228 & $-1.266 * * *$ & 0.241 & $-1.457 * * *$ & 0.227 & $-1.220 * * *$ & 0.215 \\
\hline Unemployed & $-1.317 * * *$ & 0.251 & $-1.170 * * *$ & 0.287 & $-1.323 * * *$ & 0.266 & $-1.480 * * *$ & 0.284 \\
\hline Hours underemployed & $-0.024 * * *$ & 0.008 & $-0.031 * * *$ & 0.009 & $-0.045^{* * *}$ & 0.009 & $-0.045 * * *$ & 0.010 \\
\hline Hours overemployed & $-0.041 * * *$ & 0.005 & $-0.047 * * *$ & 0.007 & $-0.050 * * *$ & 0.006 & $-0.062 * * *$ & 0.007 \\
\hline$<35 h$ & -0.009 & 0.139 & -0.058 & 0.115 & 0.208 & 0.163 & -0.063 & 0.133 \\
\hline $41 \mathrm{~h}-49 \mathrm{~h}$ & 0.086 & 0.107 & 0.107 & 0.150 & 0.118 & 0.125 & -0.041 & 0.179 \\
\hline $50+h$ & -0.028 & 0.117 & -0.131 & 0.180 & 0.110 & 0.136 & -0.215 & 0.213 \\
\hline Age: 17-24 & $1.160 * * *$ & 0.268 & $0.466^{*}$ & 0.275 & $0.687 * *$ & 0.320 & 0.543 & 0.331 \\
\hline Age: $25-34$ & $0.281^{*}$ & 0.166 & $0.321^{*}$ & 0.167 & 0.088 & 0.198 & 0.266 & 0.202 \\
\hline Age: $45-54$ & 0.240 & 0.152 & -0.259 & 0.160 & -0.012 & 0.178 & $-0.341^{*}$ & 0.192 \\
\hline Age: 55-64 & $1.052 * * *$ & 0.252 & -0.203 & 0.264 & 0.549* & 0.293 & -0.333 & 0.313 \\
\hline Married & $1.363 * * *$ & 0.133 & $1.278 * * *$ & 0.131 & $0.862 * * *$ & 0.162 & $0.794 * * *$ & 0.161 \\
\hline Number of children & 0.076 & 0.053 & $-0.103 *$ & 0.058 & -0.100 & 0.065 & $-0.208 * * *$ & 0.072 \\
\hline Disabled & $-2.008 * * *$ & 0.135 & $-2.434 * * *$ & 0.131 & $-1.709 * * *$ & 0.160 & $-2.160 * * *$ & 0.157 \\
\hline Ln real equivalized net h'hold income & 0.108 & 0.078 & $0.407 * * *$ & 0.081 & 0.090 & 0.094 & $0.295^{* * *}$ & 0.099 \\
\hline Constant & $48.978^{* * *}$ & 0.870 & $44.562 * * *$ & 0.901 & $14.504 * * *$ & 1.361 & $16.944 * * *$ & 1.239 \\
\hline Number of observations & 57,732 & & 65,14 & & 43,232 & & 49,5 & \\
\hline Number of groups & 10,758 & & 11,54 & & 8,216 & & 8,97 & \\
\hline $\mathrm{R}^{2}$ overall & 0.083 & & 0.05 & & 0.377 & & 0.36 & \\
\hline $\mathrm{R}^{2}$ within & 0.014 & & 0.015 & & 0.003 & & 0.00 & \\
\hline $\mathrm{R}^{2}$ between & 0.117 & & 0.06 & & 0.559 & & 0.58 & \\
\hline
\end{tabular}

Notes: The dependent variable is the SF-12 Mental Component Summary (MCS) score. All estimates include survey/time indicators and 2-digit ISCO occupation dummies.

* Statistically significant at the .10 level; ** at the .05 level; *** at the .01 level. 
Appendix Table A4. Fixed-effects Estimates of the Impact of Working-time Mismatch on Mental Health (SF-12): Specification I, age 25-64

\begin{tabular}{|c|c|c|c|c|c|c|c|c|}
\hline & \multicolumn{4}{|c|}{ SOEP (Germany) } & \multicolumn{4}{|c|}{ HILDA Survey (Australia) } \\
\hline & \multicolumn{2}{|c|}{ Men } & \multicolumn{2}{|c|}{ Women } & \multicolumn{2}{|c|}{ Men } & \multicolumn{2}{|c|}{ Women } \\
\hline & Coef & $S E$ & Coef & $S E$ & Coef & $S E$ & Coef & $S E$ \\
\hline Not in labor force & -0.330 & 0.316 & -0.384 & 0.296 & $-2.845^{* * *}$ & 0.434 & $-1.530 * * *$ & 0.431 \\
\hline Unemployed & $-1.079 * * *$ & 0.355 & $-1.098 * * *$ & 0.349 & $-1.884 * * *$ & 0.504 & $-1.622 * * *$ & 0.534 \\
\hline < 35h: underemployed & 0.599* & 0.350 & -0.173 & 0.256 & 0.245 & 0.356 & $-0.712 * *$ & 0.287 \\
\hline <35h: unconstrained & 0.247 & 0.412 & 0.067 & 0.240 & 0.135 & 0.322 & -0.007 & 0.233 \\
\hline <35h: overemployed & -0.268 & 0.750 & $-0.969 * * *$ & 0.303 & -0.525 & 0.739 & $-0.794 * *$ & 0.378 \\
\hline 35-40h: underemployed & -0.182 & 0.349 & -0.127 & 0.584 & -0.305 & 0.366 & 0.471 & 0.681 \\
\hline 35-40h: overemployed & $-0.598 * * *$ & 0.228 & $-0.889 * * *$ & 0.236 & $-0.731^{* * *}$ & 0.284 & $-0.840 * * *$ & 0.267 \\
\hline 41-49h: underemployed & -0.063 & 0.488 & -1.185 & 1.123 & -0.017 & 0.593 & $4.148^{*}$ & 2.242 \\
\hline 41-49h: unconstrained & $-0.584 * * *$ & 0.199 & $-0.694^{* *}$ & 0.334 & -0.106 & 0.224 & 0.423 & 0.366 \\
\hline 41-49h: overemployed & $-1.024 * * *$ & 0.174 & $-1.566 * * *$ & 0.244 & $-0.677 * *$ & 0.269 & $-0.758 * *$ & 0.344 \\
\hline 50+ h: underemployed & -0.169 & 0.705 & -1.367 & 1.973 & -0.65 & 0.761 & -3.98 & 2.819 \\
\hline 50+ h: unconstrained & -0.284 & 0.303 & -0.572 & 0.764 & 0.112 & 0.236 & -0.027 & 0.435 \\
\hline 50+ h: overemployed & $-1.016^{* * *}$ & 0.197 & $-1.716^{* * *}$ & 0.321 & $-0.879 * * *$ & 0.23 & $-1.183^{* * *}$ & 0.341 \\
\hline Age: $25-34$ & 0.124 & 0.229 & 0.041 & 0.232 & $0.774 * * *$ & 0.26 & 0.186 & 0.261 \\
\hline Age: $45-54$ & $-0.454^{* *}$ & 0.198 & 0.052 & 0.208 & 0.013 & 0.239 & -0.136 & 0.251 \\
\hline Age: 55-64 & -0.080 & 0.324 & 0.315 & 0.337 & 0.653 & 0.399 & -0.04 & 0.414 \\
\hline Married & $1.004^{* * *}$ & 0.218 & $0.784^{* * *}$ & 0.219 & $1.658 * * *$ & 0.249 & $1.791^{* * *}$ & 0.249 \\
\hline Number of children & $-0.180 *$ & 0.099 & -0.138 & 0.108 & $-0.181^{*}$ & 0.093 & -0.118 & 0.102 \\
\hline Disabled & $-1.524^{* * *}$ & 0.276 & $-1.995^{* * *}$ & 0.307 & $-2.121 * * *$ & 0.238 & $-2.738 * * *$ & 0.225 \\
\hline Ln real equivalized net h'hold income & $0.500 * * *$ & 0.172 & $0.732 * * *$ & 0.167 & 0.131 & 0.143 & $0.259 *$ & 0.148 \\
\hline Constant & $45.785 * * *$ & 1.777 & $41.385^{* * *}$ & 1.706 & $49.169 * * *$ & 1.587 & $46.236 * * *$ & 1.624 \\
\hline Number of observations & \multicolumn{2}{|c|}{37,729} & \multicolumn{2}{|c|}{41,358} & \multicolumn{2}{|c|}{21,714} & \multicolumn{2}{|c|}{24,525} \\
\hline Number of groups & \multicolumn{2}{|c|}{13,098} & \multicolumn{2}{|c|}{14,145} & \multicolumn{2}{|c|}{7,197} & \multicolumn{2}{|c|}{7,789} \\
\hline $\mathrm{R}^{2}$ overall & \multicolumn{2}{|c|}{0.022} & \multicolumn{2}{|c|}{0.035} & \multicolumn{2}{|c|}{0.083} & \multicolumn{2}{|c|}{0.071} \\
\hline $\mathrm{R}^{2}$ within & \multicolumn{2}{|c|}{0.009} & \multicolumn{2}{|c|}{0.009} & \multicolumn{2}{|c|}{0.021} & \multicolumn{2}{|c|}{0.022} \\
\hline $\mathrm{R}^{2}$ between & \multicolumn{2}{|c|}{0.025} & \multicolumn{2}{|c|}{0.040} & \multicolumn{2}{|c|}{0.102} & \multicolumn{2}{|c|}{0.075} \\
\hline
\end{tabular}

Notes: The dependent variable is the SF-12 Mental Component Summary (MCS) score. All estimates include survey/time indicators and 2-digit ISCO occupation dummies.

* Statistically significant at the .10 level; ** at the .05 level; *** at the .01 level. 
Appendix Table A5. Fixed-effects Estimates of the Impact of Working-time Mismatch on Mental Health (SF-12): Specification I, employed only

\begin{tabular}{|c|c|c|c|c|c|c|c|c|}
\hline & \multicolumn{4}{|c|}{ SOEP (Germany) } & \multicolumn{4}{|c|}{ HILDA Survey (Australia) } \\
\hline & \multicolumn{2}{|l|}{ Men } & \multicolumn{2}{|c|}{ Women } & \multicolumn{2}{|c|}{ Men } & \multicolumn{2}{|c|}{ Women } \\
\hline & Coef & SE & Coef & SE & Coef & SE & Coef & $S E$ \\
\hline < 35h: underemployed & 0.502 & 0.337 & -0.252 & 0.257 & 0.025 & 0.298 & $-0.482 *$ & 0.256 \\
\hline <35h: matched & 0.427 & 0.390 & -0.048 & 0.242 & 0.394 & 0.274 & 0.074 & 0.212 \\
\hline <35h: overemployed & -0.101 & 0.721 & $-0.985 * * *$ & 0.305 & 0.191 & 0.661 & $-0.838 * *$ & 0.359 \\
\hline 35-40h: underemployed & $-0.571^{*}$ & 0.320 & -0.123 & 0.530 & -0.324 & 0.310 & 0.195 & 0.559 \\
\hline 35-40h: overemployed & $-0.420 * *$ & 0.213 & $-1.006 * * *$ & 0.223 & $-0.670 * *$ & 0.269 & $-0.718 * * *$ & 0.251 \\
\hline 41-49h: underemployed & -0.369 & 0.444 & -0.672 & 0.980 & 0.359 & 0.506 & $3.463 * *$ & 1.661 \\
\hline 41-49h: matched & $-0.502 * * *$ & 0.188 & $-0.779 * *$ & 0.307 & -0.059 & 0.203 & 0.196 & 0.325 \\
\hline 41-49h: overemployed & $-1.059 * * *$ & 0.165 & $-1.606^{* * *}$ & 0.228 & $-0.687 * * *$ & 0.254 & $-0.625 * *$ & 0.319 \\
\hline 50+ h: underemployed & -0.364 & 0.660 & $-3.212^{*}$ & 1.902 & -0.618 & 0.667 & -1.701 & 2.462 \\
\hline 50+ h: matched & -0.160 & 0.290 & -0.111 & 0.740 & -0.001 & 0.218 & -0.192 & 0.402 \\
\hline 50+ h: overemployed & $-0.952 * * *$ & 0.190 & $-1.858 * * *$ & 0.310 & $-0.942 * * *$ & 0.217 & $-1.371^{* * *}$ & 0.322 \\
\hline Age: $17-24$ & -0.030 & 0.417 & 0.464 & 0.480 & $1.060 * *$ & 0.434 & $1.178^{* *}$ & 0.500 \\
\hline Age: $25-34$ & -0.303 & 0.234 & -0.043 & 0.281 & 0.264 & 0.265 & 0.272 & 0.311 \\
\hline Age: $45-54$ & -0.113 & 0.202 & $0.472 * *$ & 0.234 & $0.492 * *$ & 0.244 & -0.384 & 0.279 \\
\hline Age: 55-64 & 0.053 & 0.339 & $0.924 * *$ & 0.390 & $1.106 * * *$ & 0.413 & -0.201 & 0.470 \\
\hline Married & $0.904^{* * *}$ & 0.221 & $0.451^{*}$ & 0.250 & $1.471^{* * *}$ & 0.224 & $0.995^{* * *}$ & 0.245 \\
\hline Number of children & $-0.280 * * *$ & 0.098 & 0.026 & 0.128 & -0.107 & 0.089 & $-0.267 * *$ & 0.112 \\
\hline Disabled & $-1.133^{* * *}$ & 0.350 & $-1.392 * * *$ & 0.426 & $-1.112^{* * *}$ & 0.259 & $-1.599 * * *$ & 0.285 \\
\hline Ln real equivalized net h'hold income & 0.031 & 0.196 & $0.924 * * *$ & 0.207 & $0.274^{*}$ & 0.145 & $0.345^{* *}$ & 0.169 \\
\hline Constant & $51.456 * * *$ & 2.019 & $39.522 * * *$ & 2.108 & $47.735^{* * *}$ & 1.600 & $45.376^{* * *}$ & 1.853 \\
\hline Number of observations & 33,356 & & 30,23 & & 21,90 & & 20,71 & \\
\hline Number of groups & 12,177 & & 11,54 & & 7,67 & & 7,50 & \\
\hline $\mathrm{R}^{2}$ overall & 0.010 & & 0.022 & & 0.04 & & 0.00 & \\
\hline $\mathrm{R}^{2}$ within & 0.008 & & 0.011 & & 0.01 & & 0.01 & \\
\hline $\mathrm{R}^{2}$ between & 0.009 & & 0.024 & & 0.05 & & 0.00 & \\
\hline
\end{tabular}

Notes: The dependent variable is the SF-12 Mental Component Summary (MCS) score. All estimates include survey/time indicators and 2-digit ISCO occupation dummies.

* Statistically significant at the .10 level; ** at the .05 level; *** at the .01 level. 
Appendix Table A6. Fixed-effects Estimates of the Impact of Working-time Mismatch on Mental Health (SF-12): Alternative Specification

\begin{tabular}{|c|c|c|c|c|c|c|c|c|}
\hline & \multicolumn{4}{|c|}{ SOEP (Germany) } & \multicolumn{4}{|c|}{ HILDA Survey (Australia) } \\
\hline & \multicolumn{2}{|l|}{ Men } & \multicolumn{2}{|c|}{ Women } & \multicolumn{2}{|c|}{ Men } & \multicolumn{2}{|c|}{ Women } \\
\hline & Coef & $S E$ & Coef & $S E$ & Coef & $S E$ & Coef & $S E$ \\
\hline Not in labor force & -0.395 & 0.279 & $-0.457 *$ & 0.262 & $-2.176^{* * *}$ & 0.374 & $-1.091^{* * *}$ & 0.388 \\
\hline Unemployed & $-1.007 * * *$ & 0.322 & $-1.030 * * *$ & 0.314 & $-1.670 * * *$ & 0.419 & $-1.359 * * *$ & 0.466 \\
\hline Underemployed for $20+$ hours & 0.092 & 0.451 & $-0.719 *$ & 0.415 & $-1.442^{* * *}$ & 0.419 & $-1.023 * *$ & 0.471 \\
\hline Underemployed for between 15-19 hours & 0.460 & 0.658 & -0.303 & 0.435 & 0.103 & 0.495 & $-1.051^{* *}$ & 0.468 \\
\hline Underemployed for between 10-14 hours & -0.322 & 0.388 & -0.213 & 0.294 & 0.125 & 0.317 & -0.131 & 0.332 \\
\hline Underemployed for between 5-9 hours & -0.079 & 0.284 & -0.001 & 0.245 & -0.024 & 0.294 & 0.044 & 0.285 \\
\hline Underemployed for less than 5 hours & 0.000 & 0.243 & 0.026 & 0.244 & 0.430 & 0.760 & 0.065 & 0.728 \\
\hline Overemployed for less than 5 hours & $-0.399 * *$ & 0.170 & -0.233 & 0.186 & -0.902 & 0.663 & -0.940 & 0.775 \\
\hline Overemployed for between 5-9 hours & $-0.493 * * *$ & 0.168 & $-0.810 * * *$ & 0.191 & $-1.044 * * *$ & 0.224 & $-0.770 * * *$ & 0.246 \\
\hline Overemployed for between $10-14$ hours & $-0.947 * * *$ & 0.196 & $-1.323 * * *$ & 0.228 & $-0.497 * *$ & 0.211 & $-0.900 * * *$ & 0.257 \\
\hline Overemployed for between 15-19 hours & $-1.624 * * *$ & 0.270 & $-1.797 * * *$ & 0.314 & $-0.978 * * *$ & 0.288 & $-1.570 * * *$ & 0.327 \\
\hline Overemployed for $20+$ hours & $-1.558^{* * *}$ & 0.255 & $-1.873 * * *$ & 0.342 & $-0.789 * * *$ & 0.255 & $-0.863^{* *}$ & 0.350 \\
\hline$<35 h$ & 0.443 & 0.280 & -0.053 & 0.188 & $0.451^{* *}$ & 0.226 & -0.095 & 0.187 \\
\hline $41 h-49 h$ & $-0.505^{* * *}$ & 0.154 & $-0.603 * * *$ & 0.193 & 0.091 & 0.174 & 0.247 & 0.247 \\
\hline $50+h$ & -0.044 & 0.208 & -0.317 & 0.311 & -0.104 & 0.193 & -0.395 & 0.297 \\
\hline Age: 17-24 & 0.489 & 0.367 & 0.518 & 0.378 & $1.253^{* * *}$ & 0.418 & 0.499 & 0.436 \\
\hline Age: $25-34$ & -0.008 & 0.229 & 0.031 & 0.231 & $0.533^{* *}$ & 0.259 & 0.148 & 0.263 \\
\hline Age: 45-54 & -0.278 & 0.195 & 0.153 & 0.206 & 0.270 & 0.236 & -0.135 & 0.252 \\
\hline Age: 55-64 & 0.245 & 0.319 & 0.456 & 0.333 & $1.142 * * *$ & 0.393 & -0.048 & 0.413 \\
\hline Married & $0.842 * * *$ & 0.211 & $0.800 * * *$ & 0.206 & $1.214^{* * *}$ & 0.213 & $1.338 * * *$ & 0.211 \\
\hline Number of children & -0.060 & 0.090 & -0.021 & 0.096 & -0.050 & 0.084 & -0.097 & 0.093 \\
\hline Disabled & $-1.564 * * *$ & 0.272 & $-1.990 * * *$ & 0.307 & $-2.174 * * *$ & 0.227 & $-2.748 * * *$ & 0.217 \\
\hline Ln real equivalized net h'hold income & $0.345^{* *}$ & 0.145 & $0.575^{* * *}$ & 0.137 & $0.264 * *$ & 0.127 & $0.454 * * *$ & 0.131 \\
\hline Constant & $47.517^{* * *}$ & 1.490 & $42.891^{* * *}$ & 1.403 & $47.794^{* * *}$ & 1.408 & $43.836 * * *$ & 1.450 \\
\hline Number of observations & 43,683 & & 47,430 & & 26,046 & & 29,256 & \\
\hline Number of groups & 15,267 & & 16,311 & & 8,923 & & 9,588 & \\
\hline $\mathrm{R}^{2}$ overall & 0.022 & & 0.032 & & 0.084 & & 0.066 & \\
\hline $\mathrm{R}^{2}$ within & 0.009 & & 0.008 & & 0.019 & & 0.020 & \\
\hline $\mathrm{R}^{2}$ between & 0.024 & & 0.037 & & 0.106 & & 0.069 & \\
\hline
\end{tabular}

Notes: The dependent variable is the SF-12 Mental Component Summary (MCS) score. All estimates include survey/time indicators and 2-digit ISCO occupation dummies.

* Statistically significant at the .10 level; ** at the .05 level; *** at the .01 level. 
Appendix Table A7. Fixed-effects Estimates of the of Working-time Mismatch on Mental Health (SF-12): Specification I, Weighted

\begin{tabular}{|c|c|c|c|c|c|c|c|c|}
\hline & \multicolumn{4}{|c|}{ SOEP (Germany) } & \multicolumn{4}{|c|}{ HILDA Survey (Australia) } \\
\hline & \multicolumn{2}{|c|}{ Men } & \multicolumn{2}{|c|}{ Women } & \multicolumn{2}{|c|}{ Men } & \multicolumn{2}{|c|}{ Women } \\
\hline & Coef. & SE & Coef. & $S E$ & Coef. & SE & Coef. & SE \\
\hline Not in labor force & $-0.647 * *$ & 0.328 & 0.068 & 0.313 & $-2.172 *$ & 1.131 & -0.699 & 0.622 \\
\hline Unemployed & $-1.246 * * *$ & 0.389 & $-0.922 * *$ & 0.376 & $-2.009 *$ & 1.046 & -1.007 & 0.736 \\
\hline \multicolumn{9}{|l|}{ Emploved } \\
\hline < 35h: underemployed & $0.779 * *$ & 0.377 & 0.164 & 0.279 & 0.137 & 0.467 & -0.372 & 0.407 \\
\hline$<35 \mathrm{~h}$ : matched & 0.074 & 0.423 & 0.304 & 0.261 & 0.207 & 0.387 & 0.035 & 0.331 \\
\hline <35h: overemployed & -0.359 & 0.830 & $-0.754 * *$ & 0.342 & -0.448 & 1.031 & -0.664 & 0.463 \\
\hline 35-40h: underemployed & -0.026 & 0.389 & 0.020 & 0.640 & -0.329 & 0.453 & -0.413 & 0.997 \\
\hline 35-40h: overemployed & $-0.560 * *$ & 0.257 & $-0.799 * * *$ & 0.260 & $-0.874 * *$ & 0.363 & $-0.593^{*}$ & 0.353 \\
\hline 41-49h: underemployed & -0.418 & 0.562 & -0.111 & 1.128 & 0.438 & 0.875 & 2.509 & 2.598 \\
\hline 41-49h: matched & $-0.577 * *$ & 0.226 & -0.439 & 0.356 & -0.336 & 0.268 & 0.552 & 0.464 \\
\hline 41-49h: overemployed & $-1.142^{* * *}$ & 0.198 & $-1.332 * * *$ & 0.264 & $-1.128 * * *$ & 0.376 & $-0.934 * *$ & 0.468 \\
\hline $50+\mathrm{h}$ : underemployed & -0.199 & 0.799 & -3.364 & 2.146 & -1.297 & 0.878 & -4.452 & 2.872 \\
\hline $50+$ h: matched & -0.354 & 0.356 & 0.761 & 0.880 & -0.354 & 0.340 & -0.750 & 0.565 \\
\hline 50+ h: overemployed & $-1.205^{* * *}$ & 0.227 & $-1.207 * * *$ & 0.353 & $-1.094 * * *$ & 0.324 & $-1.526 * * *$ & 0.539 \\
\hline Age: $17-24$ & 0.649 & 0.447 & 0.215 & 0.456 & $1.327 * *$ & 0.659 & -0.456 & 0.642 \\
\hline Age: $25-34$ & -0.040 & 0.273 & -0.103 & 0.273 & 0.422 & 0.400 & -0.141 & 0.377 \\
\hline Age: $45-54$ & $-0.450 * *$ & 0.229 & 0.116 & 0.238 & -0.326 & 0.346 & -0.128 & 0.352 \\
\hline Age: 55-64 & -0.196 & 0.376 & 0.286 & 0.386 & 0.345 & 0.536 & 0.218 & 0.570 \\
\hline Married & $0.850 * * *$ & 0.243 & $0.654 * * *$ & 0.233 & $1.280 * * *$ & 0.377 & $1.191^{* * *}$ & 0.346 \\
\hline Number of children & -0.092 & 0.105 & -0.154 & 0.111 & 0.020 & 0.161 & -0.239 & 0.148 \\
\hline Disabled & $-1.182^{* * *}$ & 0.322 & $-1.910^{* * *}$ & 0.354 & $-2.658 * * *$ & 0.464 & $-2.638 * * *$ & 0.379 \\
\hline Ln real equivalized net h'hold income & $0.334 *$ & 0.174 & $0.560 * * *$ & 0.163 & 0.138 & 0.223 & $0.535^{* *}$ & 0.220 \\
\hline Constant & $47.618 * * *$ & 1.788 & $42.806 * * *$ & 1.666 & $49.840 * * *$ & 2.548 & $43.195 * * *$ & 2.427 \\
\hline Number of observations & \multicolumn{2}{|c|}{26,580} & \multicolumn{2}{|c|}{29,884} & \multicolumn{2}{|c|}{15,165} & \multicolumn{2}{|c|}{17,704} \\
\hline Number of groups & \multicolumn{2}{|c|}{7,091} & \multicolumn{2}{|c|}{7,965} & \multicolumn{2}{|c|}{3,204} & \multicolumn{2}{|c|}{3,654} \\
\hline $\mathrm{R}^{2}$ overall & \multicolumn{2}{|c|}{0.013} & \multicolumn{2}{|c|}{0.030} & \multicolumn{2}{|c|}{0.076} & \multicolumn{2}{|c|}{0.079} \\
\hline $\mathrm{R}^{2}$ within & \multicolumn{2}{|c|}{0.010} & \multicolumn{2}{|c|}{0.009} & \multicolumn{2}{|c|}{0.022} & \multicolumn{2}{|c|}{0.024} \\
\hline $\mathrm{R}^{2}$ between & \multicolumn{2}{|c|}{0.009} & \multicolumn{2}{|c|}{0.039} & \multicolumn{2}{|c|}{0.125} & \multicolumn{2}{|c|}{0.125} \\
\hline
\end{tabular}

Notes: The dependent variable is the SF-12 Mental Component Summary (MCS) score. All models include survey/time indicators and 2-digit ISCO occupation dummies.

* Statistically significant at the .10 level; ** at the .05 level; *** at the .01 level. 